\title{
Cellular Effects of Repetition Priming in the Aplysia Feeding Network Are Suppressed during a Task-Switch But Persist and Facilitate a Return to the Primed State
}

\author{
๑Matthew H. Perkins, -Elizabeth C. Cropper, and ๑Klaudiusz R. Weiss \\ Department of Neuroscience and Friedman Brain Institute, Icahn School of Medicine at Mount Sinai, New York, New York 10029
}

\begin{abstract}
Many neural networks are multitasking and receive modulatory input, which configures activity. As a result, these networks can enter a relatively persistent state in which they are biased to generate one type of output as opposed to another. A question we address is as follows: what happens to this type of state when the network is forced to task-switch? We address this question in the feeding system of the mollusc Aplysia. This network generates ingestive and egestive motor programs. We focus on an identified neuron that is selectively active when programs are ingestive. Previous work has established that the increase in firing frequency observed during ingestive programs is at least partially mediated by an excitability increase. Here we identify the underlying cellular mechanism as the induction of a cAMP-dependent inward current. We ask how this current is impacted by the subsequent induction of egestive activity. Interestingly, we demonstrate that this task-switch does not eliminate the inward current but instead activates an outward current. The induction of the outward current obviously reduces the net inward current in the cell. This produces the decrease in excitability and firing frequency required for the task-switch. Importantly, however, the persistence of the inward current is not impacted. It remains present and coexists with the outward current. Consequently, when effects of egestive priming and the outward current dissipate, firing frequency and excitability remain above baseline levels. This presumably has important functional implications in that it will facilitate a return to ingestive activity.
\end{abstract}

Key words: excitability; neuromodulation; priming; task-switch

\section{Significance Statement}

Under physiological conditions, an animal generating a particular type of motor activity can be forced to at least briefly taskswitch. In some circumstances, this involves the temporary induction of an "antagonistic" or incompatible motor program. For example, ingestion can be interrupted by a brief period of egestive activity. In this type of situation, it is often desirable for behavioral switching to occur rapidly and efficiently. In this report, we focus on a particular aspect of this type of task-switch. We determine how the priming that occurs when a multitasking network repeatedly generates one type of motor activity can be retained during the execution of an incompatible motor program.

\section{Introduction}

Many networks are multitasking and can generate multiple outputs (Kristan et al., 1988; Getting, 1989). When this is the case, network activity is often "sculpted" by neuromodulators so that

Received Feb. 27, 2018; revised June 1, 2018; accepted June 11, 2018.

Author contributions: M.H.P. wrote the first draft of the paper; M.H.P., E.C.C., and K.R.W. designed research; M.H.P. performed research; M.H.P., E.C.C., and K.R.W. analyzed data; E.C.C. and K.R.W. wrote the paper.

This work was supported by National Institutes of Health Grants NS066587, NS070583, and MH051393. We thank Drs. Jian Jing, Bjoern Christoph Ludwar, and Brady Trexler for technical assistance, helpful discussions, and careful critique of this manuscript.

The authors declare no competing financial interests.

Correspondence should be addressed to Dr. Matthew H. Perkins, Box 1065, Department of Neuroscience, Mount Sinai Medical Center, One Gustave L. Levy Place, New York, NY 10029. E-mail: matthew.perkins@mssm.edu. DOI:10.1523/JNEUROSCI.0547-18.2018

Copyright $\odot 2018$ the authors $\quad 0270-6474 / 18 / 386475-16 \$ 15.00 / 0$ one substance or set of substances promotes one output, whereas a second substance or set of substances promotes a different output (e.g., Harris-Warrick and Marder, 1991; Marder et al., 2005). Because effects of modulators are generally second messengermediated, modulated networks can enter a relatively persistent state in which they are biased to generate one type of activity as opposed to another. It has been suggested that this type of persistent state change can be beneficial (Cropper et al., 2017). A question less commonly addressed is as follows: what happens when modulated networks task-switch? In other words, what happens when a biased network is forced to generate a different type of output? Do persistent states "survive" the switch?

We address this question in a model system, the network that mediates feeding in the mollusc Aplysia. This network generates 
two incompatible types of outputs: egestive and ingestive motor programs (e.g., Elliott and Susswein, 2002; Cropper et al., 2004). These programs are triggered by egestive and ingestive inputs to the feeding central pattern generator (Rosen et al., 1991; Church and Lloyd, 1994; Sánchez and Kirk, 2001; Morgan et al., 2002; Cropper et al., 2004; Jing and Weiss, 2005; Proekt et al., 2005; Zhurov et al., 2005; Friedman et al., 2009, 2015; Siniscalchi et al., 2016). Central pattern generator inputs release modulatory neurotransmitters that configure network activity. Thus, stimulation of an egestive input releases one set of modulators, which creates an egestive bias to motor programs (Proekt et al., 2004, 2007; Friedman et al., 2009, 2015; Vilim et al., 2010; Wu et al., 2010; Dacks et al., 2012). Stimulation of an ingestive input releases a second set of modulators, which creates an ingestive bias (Koh et al., 2003; Proekt et al., 2004, 2007; Friedman et al., 2009; Friedman and Weiss, 2010; Dacks et al., 2012).

Our experiments focus on an identified feeding neuron (B48) that is active during ingestive motor programs but, for the most part, is inactive during egestive activity (Friedman et al., 2009). Previous work has established that the increase in firing frequency during ingestive motor programs is at least partially mediated by a persistent, modulator-induced increase in excitability (Friedman and Weiss, 2010). In this report, we identify the underlying cellular mechanism as the induction of a persistent cAMP-dependent inward current. One goal of the present study was to determine how the persistence of this current would be impacted by a task-switch (i.e., the subsequent generation of egestive motor activity). Interestingly, we use dynamic clamp techniques to demonstrate that the task-switch does not eliminate the inward current. Instead, an outward (potassium) current is induced. Addition of the outward current temporarily reduces the net inward current in the cell. This results in the decrease in excitability and firing frequency necessary for the task-switch. Importantly, however, it does not impact the persistence of the inward current. This potentially has an important functional consequence in that it facilitates a subsequent return to an ingestive pattern of activity.

\section{Materials and Methods}

\section{Animals}

Adult sea slugs (Aplysia californica) were obtained from Marinus Scientific and maintained at $14^{\circ} \mathrm{C}-15^{\circ} \mathrm{C}$. All animals used in this study were both male and female (Aplysia are hermaphrodites). Animals were anesthetized with isotonic $\mathrm{MgCl}_{2}$, and experiments were performed at $14^{\circ} \mathrm{C}-15^{\circ} \mathrm{C}$.

\section{Electrophysiological recordings}

General techniques. Preparations were superfused with artificial sea water at $0.3 \mathrm{ml} / \mathrm{min}$. Extracellular recordings were obtained using polyethylene suction electrodes connected to a Model 1700 differential AC amplifier (bandpass $0.1-1 \mathrm{kHz}$ ) (A-M Systems). Intracellular recordings were obtained using borosilicate electrodes filled with $0.6 \mathrm{M} \mathrm{K}_{2} \mathrm{SO}_{4}$ and $60 \mathrm{~mm}$ $\mathrm{KCl}$ electrolyte solution. Electrodes were pulled with a Flaming/Brown micropipette puller (Sutter Instruments) and beveled with a flowing turbid suspension of aluminum oxide to a final resistance of 7-9 MOhm. Membrane potentials and currents were measured with AxoClamp 2B amplifiers and HS-2A headstages (Molecular Devices). Intracellular and extracellular signals were digitized and digitally low-pass filtered to $1 \mathrm{kHz}$ with a 1322A Digidata (Molecular Devices). Digitized signals were recorded with AxoScope and Clampex version 9 (both from Molecular Devices). Data were analyzed using custom routines for Spike2 (Cambridge Electronic Design) and Python. Whole-cell currents were measured by two-electrode voltage clamp of B48. To limit space clamp problems, buccal nerve 3, which contains the B48 axon, was either cut or pinched in the neuropil to restrict its extent. B48 was held at $-60 \mathrm{mV}$.
Cells with membrane potentials more depolarized than $-50 \mathrm{mV}$ were not used.

Motor program induction. In vivo, Aplysia generate behaviors that can be classified as ingestive, egestive, or as having intermediate characteristics (Kupfermann, 1974; Morton and Chiel, 1993a,b; Morgan et al., 2002). In all cases, the radula (the food-grasping organ) is protracted and then subsequently retracted. Behavioral differences lie in radula opening and closing. During ingestive behaviors, the radula opens during protraction and closes during retraction, which pulls food into the buccal cavity. The opposite occurs during egestive behaviors.

In vitro, ingestive programs were induced using established procedures (e.g., Proekt et al., 2004; Friedman et al., 2009; Friedman and Weiss, 2010; Dacks et al., 2012; Dacks and Weiss, 2013; Siniscalchi et al., 2016) (see Fig. 1A). The command-like interneuron CBI-2 was activated at $9-10 \mathrm{~Hz}$ with a train of $25 \mathrm{~ms}$ DC pulses, at an amplitude that elicited one-for-one spiking. CBI-2 stimulation was terminated at the end of the protraction phase of the motor program. To identify protraction, extracellular recordings were obtained from the i2 nerve, which contains axons of radula protraction motor neurons (Hurwitz et al., 1996). To ensure that priming occurred, 6-10 trains were induced with a short (30 s) intercycle interval (ICI).

Established procedures were also used to trigger egestive motor programs (Proekt et al., 2004, 2007; Friedman et al., 2009, 2015; Siniscalchi et al., 2016). Namely, programs were triggered by stimulating the posterior branch of the esophageal nerve (EN) at $2 \mathrm{~Hz}$, with $3 \mathrm{~ms}$ constant voltage pulses.

In all motor program experiments, intracellular current-clamp recordings were obtained from the radula opener motor neuron B48, which was identified based on its location and physiological properties (Evans et al., 1996). To quantify B48's activity, its average firing frequency was computed by counting the number of action potentials during protraction and dividing by the protraction duration.

In experiments in which voltage clamp techniques were used to record currents in B48 induced during motor programs, phasic currents were evaluated by measuring the total inward current induced in B48 during protraction and subtracting any tonic current that was present (see Fig. $2 A)$. Tonic currents were measured by calculating the mean current in the $2 \mathrm{~s}$ period preceding each cycle of command neuron stimulation. Voltage clamp was performed as described below.

Electrical coupling measurements. To measure the magnitude of electrical coupling between the bilateral paired B48 neurons, one neuron was voltage-clamped (two-electrode voltage clamp) at $-60 \mathrm{mV}$, and the contralateral cell was recorded in current clamp. The electrical coupling coefficient was estimated by measuring the change in membrane potential of the current-clamped B48 due to a voltage step in the contralateral voltage-clamped B48. Two-seconds-long, $10 \mathrm{mV}$ voltage steps were made in both hyperpolarizing and depolarizing directions; no significant rectification was noted. The coupling coefficient was calculated using the hyperpolarizing steps and expressed as a percentage: Coupling Coefficient $=\left(\Delta \mathrm{V}_{\text {mem }}\right.$ B48 current clamp $/ \Delta \mathrm{V}_{\text {mem }}$ B48 voltage clamp $) \times 100$.

Excitability measurements. To test for changes in excitability, a $3 \mathrm{~s}$ constant current pulse, of sufficient amplitude to elicit $\sim 15-20$ spikes, was injected into B48 every $90 \mathrm{~s}$ until 3 consecutive tests varied by $<3$ spikes. Once preparations had stabilized, experimental manipulations were performed.

Voltage-clamp characterization of currents induced by priming. In most experiments, currents were measured using a step protocol. Steps ranged from $-100 \mathrm{mV}$ to $-20 \mathrm{mV}$ and were delivered in $10 \mathrm{mV}$ increments with an interval of 10-45 s. Steps to membrane potentials more hyperpolarized than the holding potential were applied every $10-15 \mathrm{~s}$, whereas steps to the more depolarized potentials were separated by $20-45 \mathrm{~s}$. Steadystate current-voltage curves were constructed by averaging the clamp current in the last $100 \mathrm{~ms}$ of the voltage step.

For currents that appeared to reverse during voltage steps, a voltage ramp protocol was used to measure the reversal potential. Cells were held at $-60 \mathrm{mV}$, then stepped to $-120 \mathrm{mV}$. The voltage was then ramped up to $-20 \mathrm{mV}$ at $5 \mathrm{mV} / \mathrm{s}$.

To characterize currents induced by ingestive or egestive priming, difference curves were generated by subtracting currents induced by 
Table 1. Parameters used in dynamic clamp experiments ${ }^{a}$

\begin{tabular}{|c|c|c|c|c|c|c|c|c|c|c|}
\hline & $g_{\max }(\mathrm{nS})$ & $\begin{array}{l}E_{\mathrm{rev}} \\
(\mathrm{mV})\end{array}$ & $V_{m}(m V)$ & $\mathrm{K}_{\mathrm{m}}(\mathrm{mV})$ & $\tau_{\mathrm{m}}(\mathrm{ms})$ & $p$ & $\mathrm{~V}_{\mathrm{h}}(\mathrm{mV})$ & $\mathrm{K}_{\mathrm{h}}(\mathrm{mV})$ & $\begin{array}{l}\tau_{\mathrm{h}} \\
(\mathrm{ms})\end{array}$ & 0 \\
\hline$I_{\text {Ing,L }}$ & $30 \pm 5$ & 20 & -10 & -30 & 20 & 1 & $-52 \pm 5$ & $4 \pm 1.5$ & 20 & 1 \\
\hline$I_{\text {Ing, } R}$ & $120 \pm 20$ & 10 & $-40 \pm 4$ & $-5 \pm 2.3$ & 20 & 1 & $-15 \pm 8$ & $8 \pm 3.6$ & 20 & 1 \\
\hline$I_{\text {Egest }}$ & $85 \pm 30$ & -80 & -85 & -5 & 20 & 1 & -10 & 10 & 20 & 1 \\
\hline
\end{tabular}

${ }^{a}$ Ranges indicate the SEM for a given parameter.

priming, either via stimulating CBI-2 or the EN, from currents present before priming. In CBI-2 experiments, the full set of voltage steps was delivered in each run. In EN experiments, however, this was not possible because currents are less persistent. Consequently, 3 or 4 voltage steps were delivered at a time. Preparations were rested for $10 \mathrm{~min}$ and the next series of steps applied. This was repeated until the full voltage range had been covered.

Dynamic clamp experiments. Our goal in these dynamic clamp experiments was to artificially reproduce priming activated currents in B48 neurons to ascertain the priming current's contribution to the modulation of B48 firing activity. To do this, we created an empirical model of the priming currents we measured, similar to the empirical approach applied by Farzan Nadim and colleagues (Zhao et al., 2010). In our model, parameters were selected so that the dynamic clamp currents would reproduce the currents activated by priming as measured in each preparation. Dynamic clamp experiments used the NetClamp suite of Dynamic Clamp software (RRID:SCR_016275) and a National Instruments PCI-6036E data acquisition board.

Dynamic clamp currents were calculated as follows:

$$
I_{x}=\bar{g}_{x} * m_{x}^{p} * h_{x}^{q} *\left(V-E_{x}\right)
$$

where $V$ is the membrane potential of B48, $x$ the modeled current, $m_{x}$ the activation gate, $h_{x}$ the inactivation gate, $\overline{\mathrm{g}}_{x}$ the maximum conductance, $E_{x}$ the reversal potential, and $p$ and $q$ are non-negative integers. Activation and inactivation depend on $V$ in a sigmoidal fashion as follows:

$$
\begin{gathered}
\frac{d x}{d t}=\frac{1}{\tau_{x}}\left(x_{\infty}(V)-x\right) \\
x_{\infty}(V)=\frac{1}{1+\exp \left(\left(V-V_{x}\right) / k_{x}\right)} \\
\tau_{x}=0.02
\end{gathered}
$$

Where $x$ is an activation or inaction gate (i.e., $m$ or $h$ in Eq. 1). Specifically, to model the current induced by ingestive priming, we sought to capture its three notable features: the fact that it did not reverse over the voltage range examined; the fact that appreciable current could be measured, even at hyperpolarized membrane potentials; and the fact the current induced increased with depolarization, particularly between -50 $\mathrm{mV}$ and $-20 \mathrm{mV}$. To do this, we modeled the ingestive current as a composite of two different currents.

$$
\begin{aligned}
I_{\text {Ingest }}=\bar{g}_{\text {Ing }, L} * m_{\text {Ing }, L}^{p} * & h_{\text {Ing }, L}^{q} *\left(V-E_{\text {Ing }, L}\right) \\
& +\bar{g}_{\text {Ing }, R} * m_{\text {Ing }, R}^{p} * h_{\text {Ing }, R}^{q} *\left(V-E_{\text {Ing }, R}\right)
\end{aligned}
$$

Parameters for the ingestive current in Equation 3 are listed in Table 1. Parameters for terms with the Ing, L subscript were selected such that they would contribute a relatively voltage insensitive current active in the hyperpolarized range $(-100$ to $-60 \mathrm{mV})$, making up the "left" part of the ingestive current. Parameters for terms with the Ing, $R$ subscript were selected such that they would contribute a voltage-sensitive current activating between -60 and $-20 \mathrm{mV}$, making up the "right" part of the ingestive current. The current induced by egestive priming is less complex. It reversed and showed modest voltage activation from between -60 to $-20 \mathrm{mV}$. A single-model current with voltage-dependent activation and inactivation captured these features as follows:

$$
I_{E g s t}=\bar{g}_{E g s t} * m_{E g s t}^{p} * h_{E g s t}^{q} *\left(V-E_{E g s t}\right)
$$

Parameters for the egestive current in Equation 4 are also listed in Table 1. When simultaneous dynamic clamp current and constant current injections were required, the constant current injection was generated via a TTL trigger to the step command input of the AxoClamp 2B, which sums with the second command input, which was connected to the National Instruments board. The dynamic clamp frequency was set at $5 \mathrm{kHz}$. Empirical models of currents were constructed using voltage-clamp data.

Iontophoresis of Rp-cAMP. In Rp-cAMP loading experiments, B48 was impaled with a third electrode (in addition to the two voltage-clamp electrodes). The third electrode contained either $40 \mathrm{~mm}$ Rp-cAMP (experimental condition) or normal filling solution (control condition). Rp-cAMP (or $\mathrm{SO}_{4}$ ) was loaded iontophoretically, by passing $-90 \mathrm{nA}$ of current for $60 \mathrm{~s}$, with the cell voltage-clamped at $-60 \mathrm{mV}$.

\section{Reagents}

Experiments were conducted in artificial sea water with the following composition (in mM as follows: $460 \mathrm{NaCl}, 10 \mathrm{KCl}, 55 \mathrm{MgCl}_{2}, 11 \mathrm{CaCl}_{2}$, and 10 HEPES buffer, $\mathrm{pH}$ 7.6). Rp-cAMP was purchased from Sigma-Aldrich.

\section{Statistical analyses}

Statistical analysis was performed with R. Error bars indicate SEM. When ANOVA tests indicated significant effects, further individual comparisons were performed with a Welch's or Student's $t$ test, and $\alpha=0.05$ and $p$ values were adjusted with a Holm-Sidak correction, or Dunnett's correction where specified. Deviations from normal distributions were identified with the Shapiro-Wilk test.

\section{Results}

\section{Inward currents induced in B48 during ingestive priming}

Previous work established that ingestive motor programs can be triggered in the feeding network of Aplysia by stimulating a command-like neuron (the neuron CBI-2) (e.g., Rosen et al., 1991; Church and Lloyd, 1994; Sánchez and Kirk, 2001; Morgan et al., 2002; Proekt et al., 2004). However, for the most part, this is only true if cycles of motor activity are repeatedly induced with a relatively short ICI (Proekt et al., 2004). Under these conditions, modulatory neurotransmitters are released (including the peptides FCAP and CP-2) (Koh et al., 2003). Modulators act on the feeding circuitry to progressively alter motor activity (Koh et al., 2003; Proekt et al., 2004, 2007; Friedman et al., 2009; Friedman and Weiss, 2010; Dacks et al., 2012). Thus, the first cycle that is triggered is not well articulated and is referred to as having intermediate characteristics. However, successive cycles become more and more ingestive. This phenomenon has been referred to as ingestive repetition priming.

Ingestive priming involves repatterning of activity in the circuitry that opens and closes the food-grasping organ in Aplysia, the radula (Morton and Chiel, 1993a,b). During all feeding behaviors, the radula is initially protracted and then subsequently retracted. Ingestive behaviors differ from egestive behaviors in that, during ingestive behaviors, the radula opens during protraction and closes during retraction. This pulls food into the buccal cavity. During egestive behaviors, the radula closes during protraction and opens during retraction. This pushes food out.

The current study focuses on a radula opener motor neuron, B48. Previous work has established that, as ingestive priming develops, there are progressive changes in the B48 firing frequency (Fig. 1B) (Friedman et al., 2009; Friedman and Weiss, 2010). Initially, B48 fires at a frequency that does not effectively open the radula. As priming continues, the B48 firing frequency increases and the radula is opened. Previous work has also established that this change in firing frequency is accompanied by an increase in intrinsic excitability. An unanswered question, however, is whether this excitability increase is the sole, or at least the major, determinant of the firing frequency increase. (A large pro- 
gressive increase in excitatory synaptic input would be an alternative possibility.)

To address this question, we induced ingestive priming and recorded from both the left and right B48 neurons. One B48 recording was obtained under current-clamp conditions and was used to monitor firing frequency and verify that priming had occurred (Fig. 2A, B48cc). The B48 firing frequency did progressively increase $\left(F_{(8,70)}=\right.$ 17.28, $N=10, p<0.001$ ) (Fig. $2 A$ ). It was $2.42 \pm 0.32 \mathrm{~Hz}$ in the first program and $7.1 \pm 0.49 \mathrm{~Hz}$ in the last $\left(_{(9)}=11.92\right.$, $p<0.001)$.

The other B48 recording was obtained under voltage-clamp conditions and was used to characterize changes in inward currents in B48 during priming (Fig. 2A, $\mathrm{B} 48 \mathrm{vc})$. We quantified changes in two "types" of currents: a protraction-specific (phasic) current and a sustained (tonic) current. Phasic currents are relatively large inward currents that are induced by the fast excitatory synaptic input B48 receives during the protraction phase of the motor program (Friedman et al., 2009) (Fig. 2A, black I-beam). Tonic currents are persistent inward currents that outlast cycles of motor activity and are most apparent in ICIs (Fig. $2 \mathrm{~A}$, pink I-beam). This type of current is most likely to be responsible for the reported persistent increase in excitability.

During priming, the tonic current increased from $0.29 \pm 0.31$ $\mathrm{nA}$ just before the first cycle of motor activity, to $-1.28 \pm 0.33 \mathrm{nA}$ just before the last cycle of activity $\left(t_{(9)}=10.23, N=10, p<\right.$ $0.001)$. This represents an increase of $1.58 \pm 0.15 \mathrm{nA}$ in the inward direction (Fig. $2 B$, pink plot). There was also a significant increase in the phasic current: it went from $-2.16 \pm 0.2 \mathrm{nA}$ in the first program, to $-2.86 \pm 0.41 \mathrm{nA}$ in the last program $\left(t_{(9)}=2.36\right.$, $N=10, p=0.043$ ) (Fig. 2B, black plot). The increase in the tonic current was significantly larger than the increase in the phasic current $\left(t_{(9)}=3.57, N=10, p=0.006\right)$.

An increase in a tonic inward current would be expected to depolarize B48. To determine whether this occurs, we analyzed the current-clamp recording and determined the B48 membrane potential before and after ingestive priming. Priming did depolarize B48. On average, its membrane potential was $-60.7 \pm 2.2$ $\mathrm{mV}$ before priming and $-48.33 \pm 1.6 \mathrm{mV}$ after priming $\left(t_{(9)}=\right.$ $-9.71, N=10, p<0.001$ ) (Fig. $2 A, B 48 c c$ trace). Because the two B48 neurons are electrically coupled, this depolarization should contribute a small tonic current to the contralateral B48. To estimate this contribution, we measured the coupling coefficient between the two B48s. Based on the coupling coefficient (8.3 \pm $0.4 \%, N=6$ ), the depolarization of the current-clamp B48 would be expected to contribute $0.08 \mathrm{nA}$ of inward current to the voltage-clamped B48. To summarize, our data show that there are progressive changes in phasic currents in B48 during repetition priming. However, these changes are small compared with the tonic current that develops.

To more directly relate changes in phasic and tonic currents to alterations in firing frequency, we generated the plots shown in Figure $2 C$. Visual inspection of these plots suggests that the relationship between current induction and firing frequency changes
B

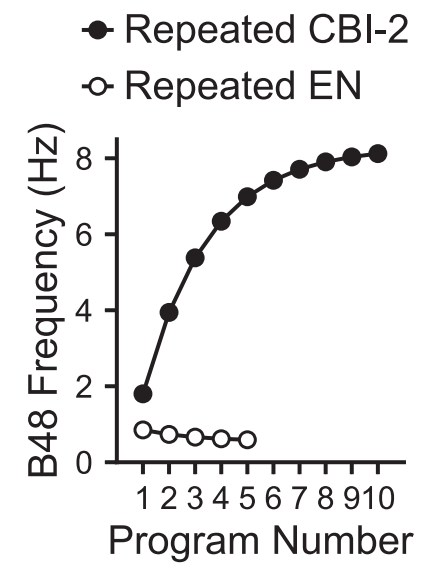

Program Number

Figure 1. Network activity during motor programs changes with priming. $\boldsymbol{A}$, One cycle of ingestive motor program activity triggered by stimulating the command-like interneuron CBI-2 (top). The cycle has two phases: radula protraction (black bar below the B48 firing frequency when cycles of motor activity are triggered by stimulating CBI-2 with a relatively short ICl. Open circles grequency that occur when the $\mathrm{EN}$ is stimulated with a relatively short $\mathrm{ICl}$.

over time. Consequently, we calculated one piecewise fit of the data for the first cycles of motor activity (cycles 1-4) and a second fit for the last cycles (cycles 5-9).

The plot of the first half of the tonic current data is well fit by a line that has a non-zero slope ( lope $=0.44, t_{(3)}=14.903, p<$ 0.001 ) (Fig. 2C, 1-4 in pink plot). In contrast, the slope of the plot of the first half of the phasic current is virtually zero ( slope $=0.05$, $\left.t_{(3)}=1.63, p=0.2\right)$ (Fig. $2 C, 1-4$ in black plot). This suggests that it is the change in the magnitude of the tonic current that plays the major role in determining firing frequency during the first cycles of motor activity.

The situation changes during the last cycles of motor activity. In this case, the plot of the tonic current data is fit by a line that has a slope that is virtually zero ( lope $=0.04, t_{(3)}=0.38, p=$ 0.73) (Fig. 2C, 5-9 in pink plot). In contrast, it is the plot of the phasic current data that is fit by a line with a positive slope (slope $=0.39, t_{(3)}=4.58, p=0.02$ ) (Fig. 2C, 5-9 in black plot). Thus, although the tonic current appears to be the major determinant of firing frequency during the first cycles of motor activity, during the last cycles of activity, progressive increases in firing frequency appear to be primarily due to increases in phasic currents.

During cycles 1-4, the B48 firing frequency starts at $2.42 \pm$ $0.32 \mathrm{~Hz}$ and ends at $6.07 \pm 0.66 \mathrm{~Hz}$. This change in firing frequency will produce a significant increase in the magnitude of radula opening (i.e., previous data predict a change of $\sim 1.0 \mathrm{~mm}$ ) (Friedman et al., 2009). During later cycles (i.e., 5-9), the B48 firing frequency continues to increase and eventually reaches $7.1 \pm 0.49 \mathrm{~Hz}$. This is a smaller increase (i.e., during the first cycles, the frequency is increased by $3.65 \pm 0.49 \mathrm{~Hz}$; and during the later cycles, it is increased by $1.27 \pm 0.83 \mathrm{~Hz}$ ). Moreover, although a further increase in the magnitude of radula opening would be predicted, it is likely to be relatively small (i.e., previous data suggest that it will only be $\sim 0.1 \mathrm{~mm}$ ) (Friedman et al., 2009). Together, these data suggest that most of the firing frequency increase observed during ingestive repetition priming is due to the induction of a tonic (sustained) current. 
A Cycle 1
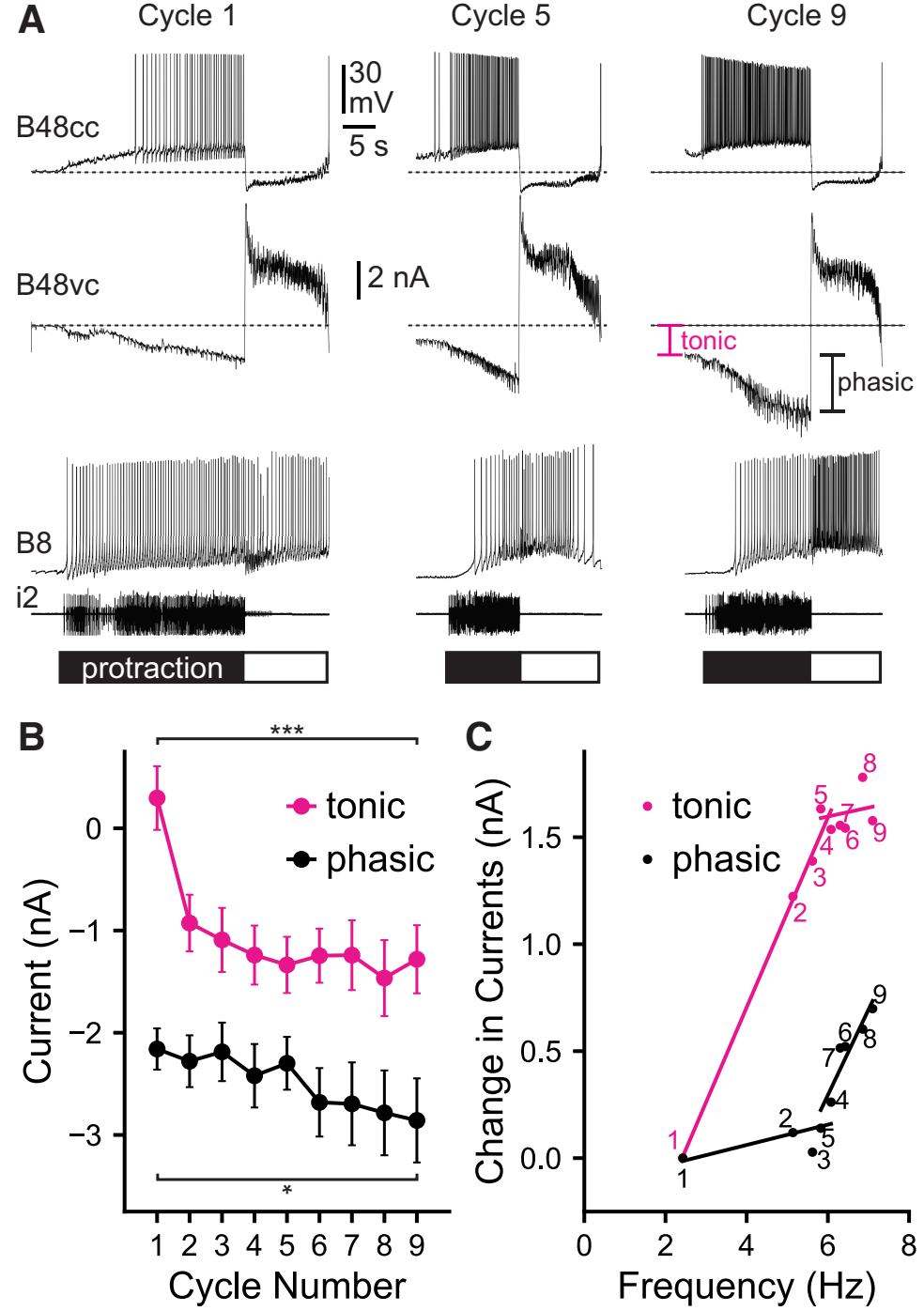

Figure 2. Currents induced in B48 during ingestive priming. $A$, A series of 9 cycles of motor activity were triggered by stimulating (BI-2 with a $30 \mathrm{sICl}$. Cycles 1, 5, and 9 are shown. Top three traces represent, from top to bottom, a current-clamp recording from a B48 neuron (B48cc), a voltage clamp recording from the contralateral neuron clamped at $-70 \mathrm{mV}$ (B48vc), and an intracellular recording from the radula closer motor neuron B8. Bottom, Extracellular recording from the i2 nerve. Dotted lines that run through the B48cc recordings indicate the resting potential ( $-53 \mathrm{mV}$ ). Dotted lines that run through the B48vc recordings indicate the baseline holding current. Pink bar represents the sustained current that developed before cycle 9 (tonic current). Black bar represents the peak synaptic current induced during the protraction phase of cycle 9 (phasic current). As ingestive priming develops, there are progressive increases in the B48 firing frequency. Further, there are increases in both tonic and phasic currents $(N=7)$. $B$, Plot of cycle number versus tonic current (pink) or synaptic current (black). Priming produces a significant increase in both types of currents, but the increase in the tonic current is larger $(N=7)$. $C$, Data shown in $B$ are replotted with the change in the magnitude of the current on the ordinate and the $B 48$ firing frequency on the abscissa. Mean values are plotted for each cycle number, and error bars are omitted for clarity. Data were divided into two groups: data for cycles $1-4$ and data for cycles $5-9$. Each group was fit with a line and the slope calculated as described in the text $(N=7) .{ }^{* *} p<0.001,{ }^{*} p<0.05$. repeated $\mathrm{CBI}-2$ stimulation, the number of spikes increased to $46.28 \pm 4.82(N=7$, $\left.t_{(12)}=8.16, p<0.001\right)$. At $38 \mathrm{~min}$, the number of evoked spikes was reduced by $60 \%$ but was still significantly above baseline $\left(t_{(12)}=3.3, p=0.013\right.$, Dunnett's).

Excitability changes after egestive priming A major question of interest in this study was what will happen to persistent changes in B48's intrinsic properties induced by ingestive priming if the feeding network is forced to task-switch (i.e., generate egestive motor programs). Previous work has established that egestive motor programs can be triggered in previously quiescent preparations by repeated stimulation of an egestive input to the feeding central pattern generator, the EN (e.g., Proekt et al., 2004; Friedman et al., 2009). During egestive priming, the B48 firing frequency remains low so that radula opening during protraction does not occur (Fig. 1B). Food is most efficiently pushed out of the buccal cavity if the radula protracts closed.

To determine whether egestive repetition priming results in a change in B48 excitability, we injected constant current pulses and counted the number of induced spikes before and after repeated stimulation of the EN. In rested preparations, $13 \pm 2.23$ spikes were evoked, whereas $3.66 \pm 1.31$ spikes were triggered $30 \mathrm{~s}$ after repeated EN stimulation $(N=6$, $t_{(10)}=-3.43, p=0.009$ ) (Fig. $3 A$, orange plot). This reduction in B48 excitability persisted but dissipated more quickly than effects of ingestive priming. For example, 12 minutes after EN stimulation, current pulses triggered $11.33 \pm 3.08$ spikes, which was not significantly different from the number of spikes triggered in rested preparations $\left(N=6, t_{(10)}=-0.61\right.$, $p=0.99$, Dunnett's). These data indicate that egestive priming is like ingestive priming in that it results in a persistent change in B48's intrinsic properties. With the stimulation paradigms used, however, effects of ingestive priming outlast effects of egestive priming (Fig. $3 A$ ).

\section{Persistent changes in B48 excitability induced by priming} Excitability changes after ingestive priming

The induction of a sustained inward current would be expected to produce a persistent increase in excitability. Indeed, a previous study demonstrated that a single, $10 \mathrm{~s}$ burst of action potentials in CBI-2 induced a change in B48's excitability that lasted for minutes (Friedman and Weiss, 2010). To characterize effects of repeated CBI-2 stimulation (i.e., ingestive priming), we measured the B48 excitability before and after 10 cycles of motor activity (Fig. 3A, black plot). After priming, B48's excitability remained elevated for at least $38 \mathrm{~min}$. Thus, in rested preparations, constant current pulses evoked $13.71 \pm 1.7$ spikes in B48; and $30 \mathrm{~s}$ after
Excitability changes after an ingestive-egestive task-switch

To determine how B48 excitability is impacted by a task-switch, we repeatedly stimulated CBI-2 and measured excitability $30 \mathrm{~s}$ later to verify that ingestive priming had occurred. We then repeatedly stimulated the EN and measured excitability $30 \mathrm{~s}$ later, and then every $90 \mathrm{~s}$ until it returned to control levels (Fig. 3A, green plot). To determine whether EN stimulation had an impact, we used a two-way ANOVA to compare the data obtained when CBI-2 was stimulated alone (Fig. $3 A$, black plot) with the data obtained when both CBI-2 and the EN were stimulated (Fig. $3 A$, green plot). Excitability did indeed differ $\left(F_{(1,152)}=19.09\right.$, 
$p<0.001)$. Thus, EN stimulation altered excitability, even when egestive priming was preceded by ingestive priming.

When the EN is stimulated on its own, B48 excitability returns to baseline levels after $12 \mathrm{~min}$ (Fig. $3 \mathrm{~A}$, orange plot). In contrast, when only CBI-2 is stimulated, excitability is still elevated at this time point (Fig. 3A, black plot). Therefore, we compared the effect of a task-switch on B48 excitability with that of CBI-2 priming alone, selecting matched observations from the 12 min time point until recovery. This comparison is informative because it indicates whether effects of EN stimulation "erase" effects of CBI-2 stimulation or only "suppress" them. If effects of CBI-2 stimulation have been erased, excitability should return to baseline levels after the effect of EN stimulation has faded. In contrast, if effects of CBI-2 stimulation have only been suppressed, excitability should still be elevated at $12 \mathrm{~min}$ after EN stimulation and should gradually return to baseline levels. When we used an ANOVA to compare the $12 \mathrm{~min}$ on data, we found no significant effect of EN stimulation $\left(F_{(1,125)}=0.072, p=0.79\right)$. This indicates that, in effect, the CBI-2 elicited enhancement of B48 excitability reemerges following a transient suppression immediately after EN stimulation. This suggests that EN stimulation does not erase persistent effects of ingestive priming but instead suppresses them.

\section{Changes in B48's firing frequency}

induced by a task-switch

In the experiments above, "suppressive" effects of EN stimulation were demonstrated in terms of excitability changes in B48. An obvious follow-up question is as follows: would these changes in excitability be sufficient to modify the B48 firing frequency during motor programs? To address this question, we conducted a second set of "task-switch" experiments, but instead of measuring excitability, we triggered test motor programs at time points of interest and measured the mean firing frequency of B48 during the protraction phase of the motor program.

In one group of animals, we monitored the B48 firing frequency during ingestive priming, stimulated EN, and triggered a test motor program shortly thereafter (i.e., at $30 \mathrm{~s}$ ) to verify the efficacy of EN stimulation (Fig. 4A1). Additionally, we triggered a cycle of motor activity at 60 min to test for recovery. In control experiments, we induced ingestive priming with no subsequent EN stimulation and determined the B48 firing frequency at matched time points (Fig. $4 A 2$ ). Data were compared using a two-way ANOVA and did

B2
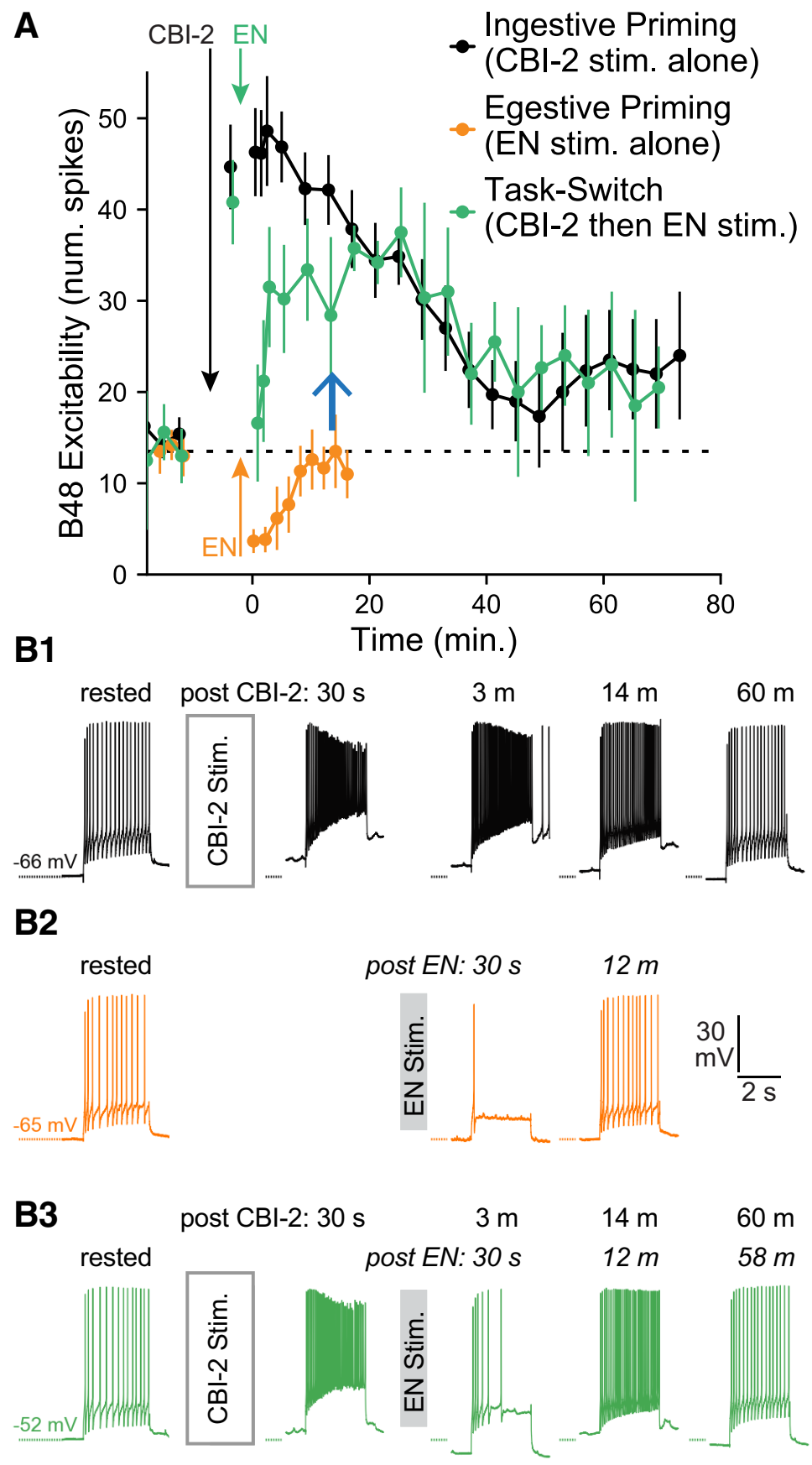

Figure 3. Effects of priming and a task-switch on the B48 excitability. Excitability was measured by injecting a 3 s current pulse into B48 every $90 \mathrm{~s}$, except during control periods and periods of input activation. Ingestive priming was induced by triggering 10 cycles of motor activity via CBI-2 stimulation with a short ICI. Egestive priming was induced by stimulating the EN for $2 \mathrm{~min}$, which elicited $\sim 5$ cycles of motor activity. In task-switch experiments, we induced ingestive priming and then switched to egestive priming. $A$, Plots of group data. Black represents excitability before and after ingestive priming $(N=7)$. Orange represents excitability before and after egestive priming $(N=6)$. Green represents excitability before and after the task-switch $(N=5)$. Ingestive priming produced a persistent excitability increase that lasted $\sim 38 \mathrm{~min}$. Egestive priming produced an excitability decrease that lasted $\sim 12 \mathrm{~min}$. In the task-switch paradigm, excitability was initially increased by ingestive priming. When the EN was stimulated, excitability immediately decreased. However, after $\sim 12 \mathrm{~min}$, effects of EN stimulation were no longer apparent (time point marked by blue arrow). Excitability was above baseline levels and was not significantly different from excitability in preparations in which there was no task-switch (green vs black plot). $\boldsymbol{B}$, Sample intracellular recordings from B48 before and after ingestive priming (B1), egestive priming (B2), and a task-switch (B3).

differ $\left(F_{(1,48)}=7.4, p=0.01, N=7\right)$ (Fig. $4 A 3$ ). Further, there was an interactive effect of paradigm (EN vs no EN) and cycle number $\left(F_{(3,48)}=11.06, p<0.001\right)$. Importantly, the B48 firing frequency at $30 \mathrm{~s}$ was significantly lower when the EN was stim- 

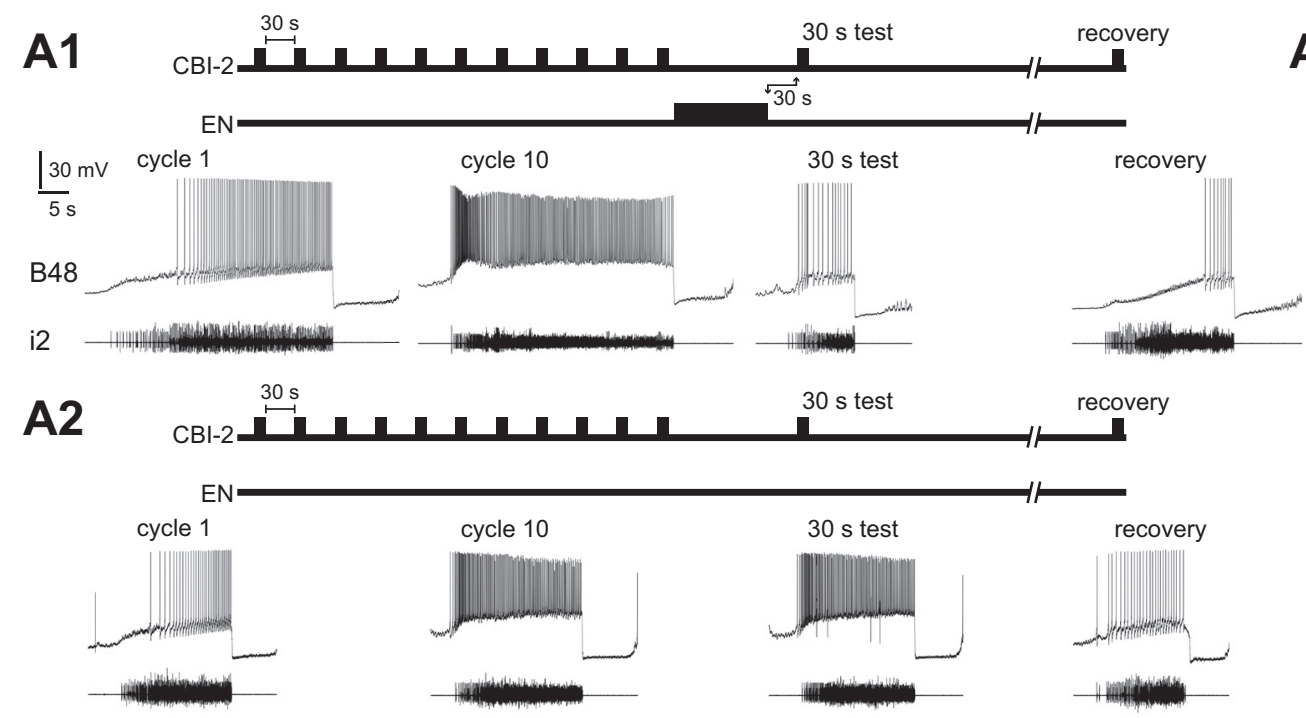

A3

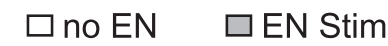

\section{B1}

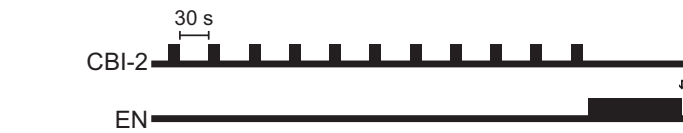

$12 \mathrm{~m}$ test recovery

trm

1
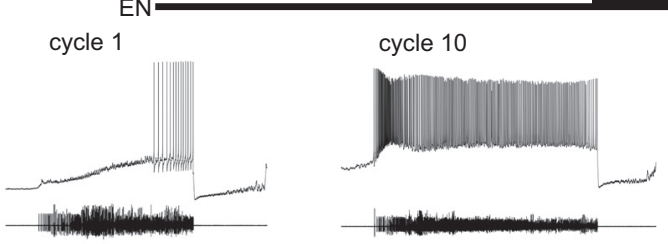

$12 \mathrm{~m}$ test

recovery

B2
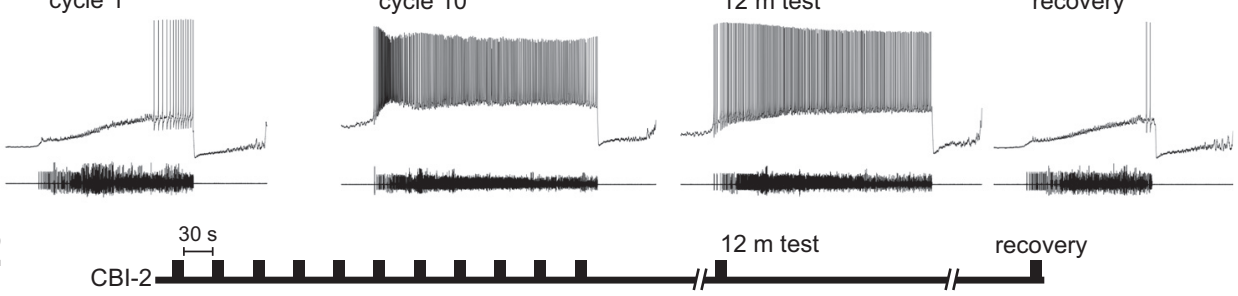

B3
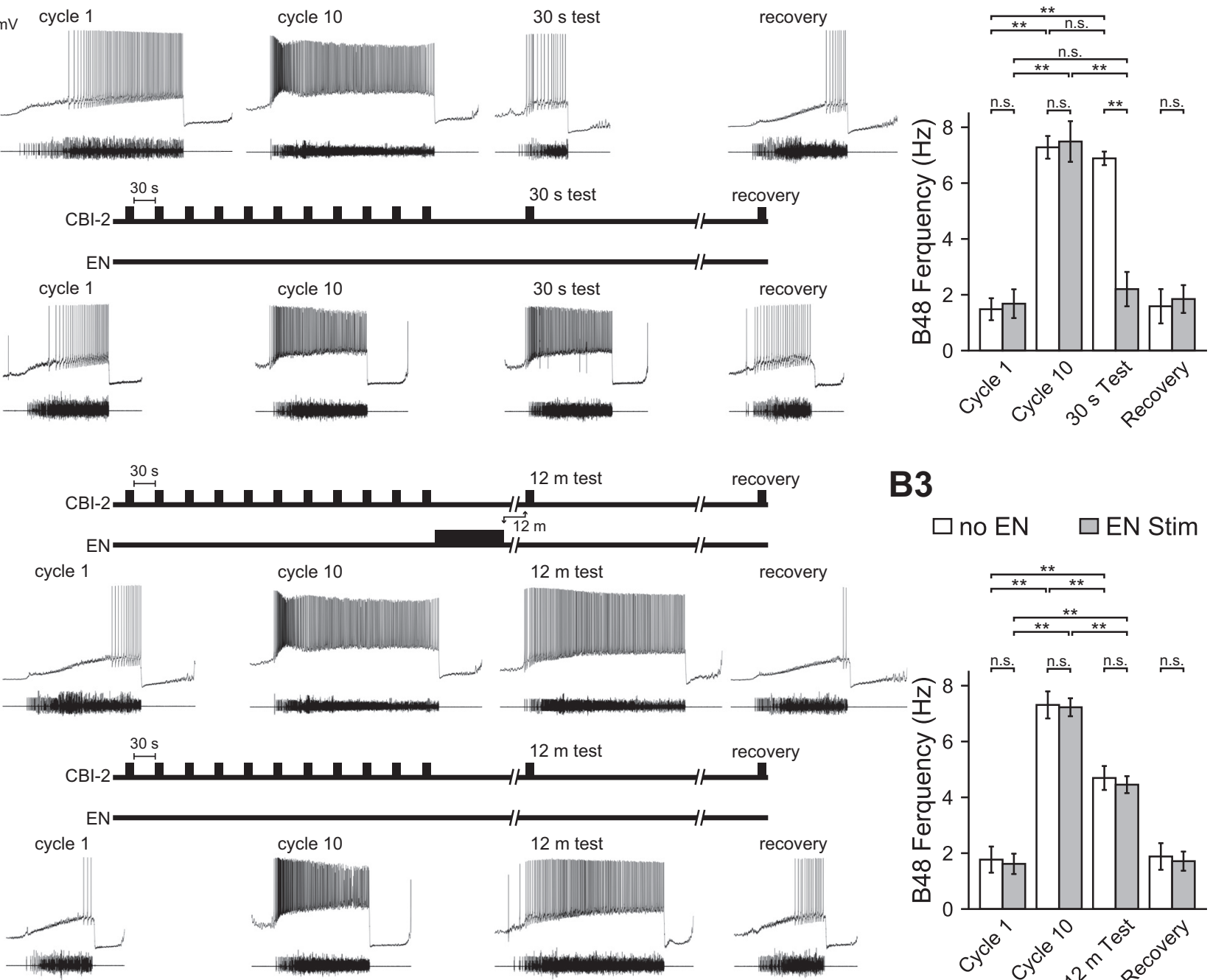

$12 \mathrm{~m}$ test

tr

recovery
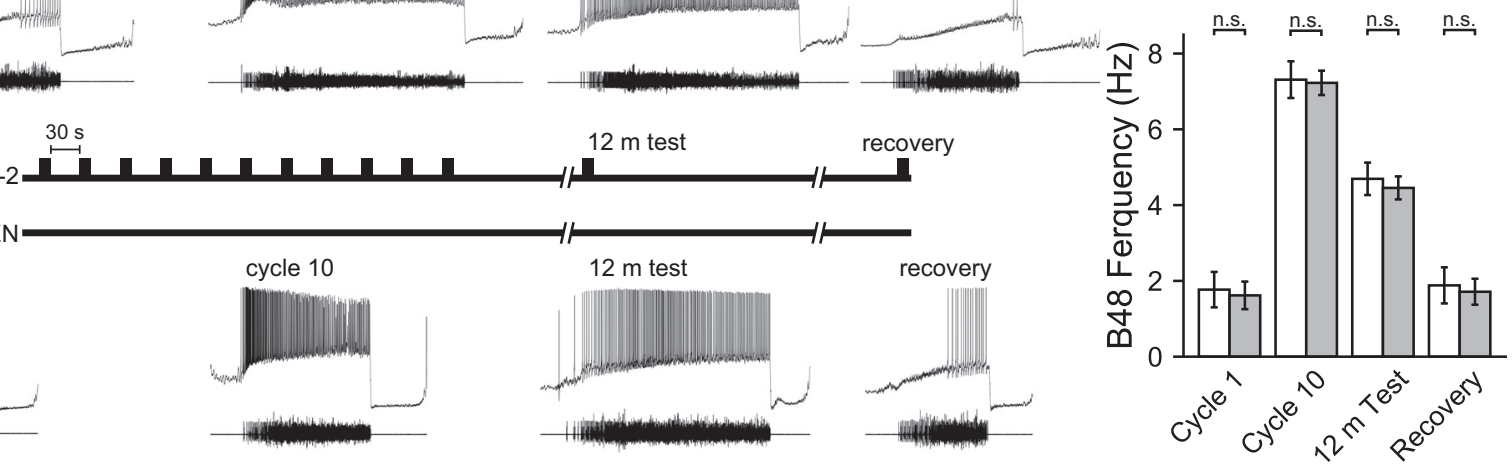

Figure 4. Changes in B48 excitability are sufficient to modify B48 activity during motor programs. $\boldsymbol{A}$, Immediate impact of a task-switch on B48 firing frequency. A1, A2, Top two lines indicate the experimental protocol. Bottom, Sample recordings. Top, Intracellular recording from B48. Bottom, Extracellular recording from the i2 nerve. $\mathbf{A 1}$, $\mathbf{A 2}$, Ingestive priming was induced by triggering 10 cycles of motor activity by stimulating $\mathrm{CBI}-2$ with a short ( $30 \mathrm{~s}$ ) ICl. $\mathbf{A}$ 1, There was a task-switch: the EN was stimulated for $2 \mathrm{~min}$, and firing frequency was measured shortly thereafter ( $30 \mathrm{~s}$ test). $\boldsymbol{A 2}$, The EN was not stimulated. Instead, there was a 2 min break so that the first measurement was made at a comparable time point. $\boldsymbol{A} \mathbf{3}$, Group data for $\boldsymbol{A} \mathbf{1}$ and $\boldsymbol{A 2}$. White bars represent data obtained without the task-switch. Gray bars represent data obtained with the task-switch. When there was a task-switch, there was a significant decrease in firing frequency $(N=7) . \boldsymbol{B}$, The impact of the task-switch on persistent changes in B48 induced by ingestive priming. B1, B2, Top two lines indicate the experimental protocol. Bottom, Sample recordings. Top, Intracellular recording from B48. Bottom, Extracellular recording from the i2 nerve. Ingestive and egestive priming was induced as described in $\boldsymbol{A}$. There was a task-switch in $\boldsymbol{B} \mathbf{1}$ but not $\boldsymbol{B 2}$. $\boldsymbol{B} \mathbf{1}$, Firing frequency was measured 12 min after the end of EN stimulation (12 min test). $\boldsymbol{B}$, Firing frequency was measured at a comparable time point. $\boldsymbol{B}$, Group data for $\boldsymbol{B} \mathbf{1}$ and $\boldsymbol{B} \mathbf{2}$. White bars represent data obtained without the task-switch. Gray bars represent data obtained with the task-switch. The task-switch had no significant effect on frequency at $12 \min (N=10$ or 11$) .{ }^{* *} p<0.001$.

ulated $(2.2 \pm 0.62 \mathrm{~Hz}$ vs $6.89 \pm 0.24 \mathrm{~Hz})\left(t_{(12)}=7.1 p<0.001\right)$. These data demonstrate that, even in the task-switch paradigm, EN-induced reductions in excitability are sufficient to modify the B48 firing frequency.

In a second group of animals, we performed a similar type of experiment but triggered a test program at $12 \mathrm{~min}$ (i.e., at the time point used to determine whether EN stimulation erases or suppresses effects of ingestive priming on excitability) (Fig. $4 B 1, B 2)$. Again, data were compared using a two-way ANOVA (Fig. 4B3). In this case, there was no effect of EN stimulation $\left(F_{(1,76)}=0.3, p=0.58, N=10\right.$ or 11$)$, and no interaction between paradigm and program $\left(F_{(3,76)}=0.012, p=0.99\right)$. Post hoc tests indicated that the $\mathrm{B} 48$ firing frequency at 12 min was significantly elevated both when the EN was stimulated and when it was not.
When the EN was stimulated, B48 fired at $4.45 \pm 0.3 \mathrm{~Hz}$ at $12 \mathrm{~min}$ as opposed to a baseline firing frequency of $1.62 \pm 0.36 \mathrm{~Hz}\left(t_{(9)}=\right.$ $6.36, p<0.001)$. When the $\mathrm{EN}$ was not stimulated, B48 fired at $4.69 \pm 0.43 \mathrm{~Hz}$, as opposed to a baseline firing frequency of $1.78 \pm 0.47 \mathrm{~Hz}\left(t_{(10)}=8.5, p<0.001\right)$. These data are consistent with the idea that EN stimulation suppresses, rather than erases, persistent effects of CBI-2 stimulation.

\section{Characterization of persistent currents induced by ingestive} and egestive priming

Net inward current induced by ingestive priming

To further probe the idea that effects of EN stimulation are mediated via "suppression," we further characterized cellular mechanisms mediating both ingestive and egestive priming. Our 
motor program data suggest that ingestive priming results from the induction of a persistent inward current (Fig. 2A-C). To characterize this current, B48 was voltageclamped at a holding potential of $-60 \mathrm{mV}$ and its steady-state current-voltage relationship was determined by applying $2 \mathrm{~s}$ command steps that ranged from -100 to $-20 \mathrm{mV}$ in $10 \mathrm{mV}$ increments (Fig. $5 \mathrm{~A}, \mathrm{C}$, paradigm). Command steps were delivered before priming and at selected time points after. Time points tested were $30 \mathrm{~s}$ (when maximal excitability increases are observed), $10 \mathrm{~min}$ (when excitability increases have dissipated somewhat), and $60 \mathrm{~min}$ (when excitability increases are no longer observed). The CBI-2-induced current was computed by subtracting currents measured in the rested preparation from the currents measured after 10 cycles of CBI-2 stimulation with a $30 \mathrm{~s}$ interstimulus interval (Fig. 5F, blue/green data).

CBI-2 stimulation induced an inward current that did not reverse between -100 and $-20 \mathrm{mV}$ and was voltagedependent (i.e., the amount of current induced was greatest at relatively depolarized potentials) (one-way ANOVA, $N=$ $7, F_{(8,54)}=12.65, p<0.001$; Fig. $\left.5 C, E, F\right)$. For instance, the current at $-60 \mathrm{mV}$ was $-1.76 \pm 0.26 \mathrm{nA}$, whereas the current at $-30 \mathrm{mV}$ was $-4.1 \pm 0.6 \mathrm{nA}\left(N=7, t_{(6)}=\right.$ $-4.44, p<0.001)$. Further, the induced current was persistent and dissipated over time (two-way ANOVA, $N=5, F_{(2,8)}=$ $35.3, p<0.001)$. For example, $10 \mathrm{~min}$ after priming, a significant amount of current remained at both the holding potential $\left(N=5, t_{(4)}=-4.05, p=0.016\right)$ and at the step to $-30 \mathrm{mV}\left(N=5, t_{(4)}=\right.$ $-5.8, p=0.004)$. At $60 \mathrm{~min}$, the inward current was no longer apparent at either the holding potential $\left(N=5, t_{(4)}=1.4\right.$, $p=0.23)$ or at the step to $-30 \mathrm{mV}(N=5$, $\left.t_{(4)}=0.69, p=0.52\right)$. This time course parallels the increases in excitability and firing frequency observed after ingestive priming.

Net outward current induced by egestive priming

If egestive priming suppresses, rather than erases, effects of ingestive priming, we would expect EN stimulation to induce a distinct outward current, rather than eliminate the CBI-2 induced inward current. To determine whether this is the case, we injected the same set of command steps into B48 neurons in rested preparations and at selected time points after EN stimulation. Time points selected in these experiments were $30 \mathrm{~s}$, when maximal ex-
A

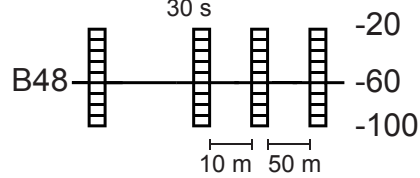

B
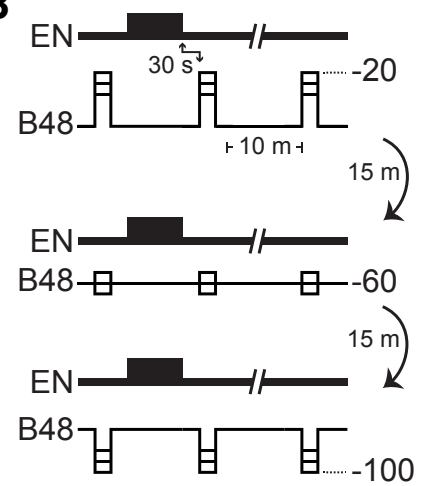

C $\begin{array}{lccc}\text { rested } & 30 \mathrm{~s} & 10 \mathrm{~m} & 60 \mathrm{~m} \\ \text { post } & \text { post } & \text { post } \\ \text { CBI-2 } & \text { CBI-2 } & \text { CBI-2 }\end{array}$
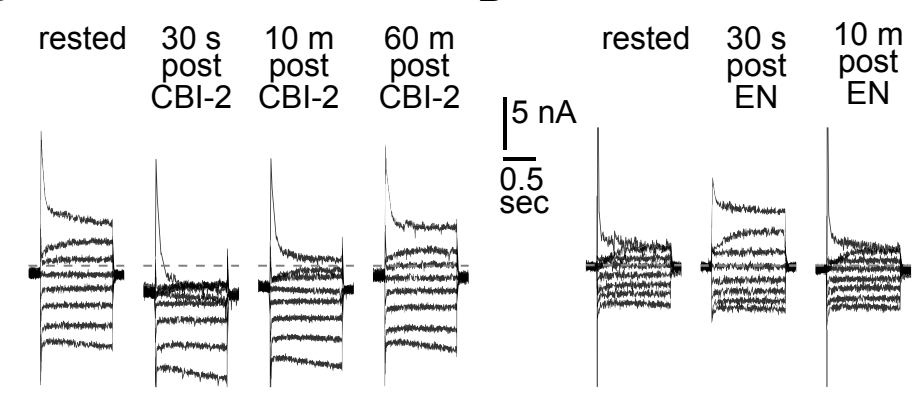

E

$\mathbf{F}$
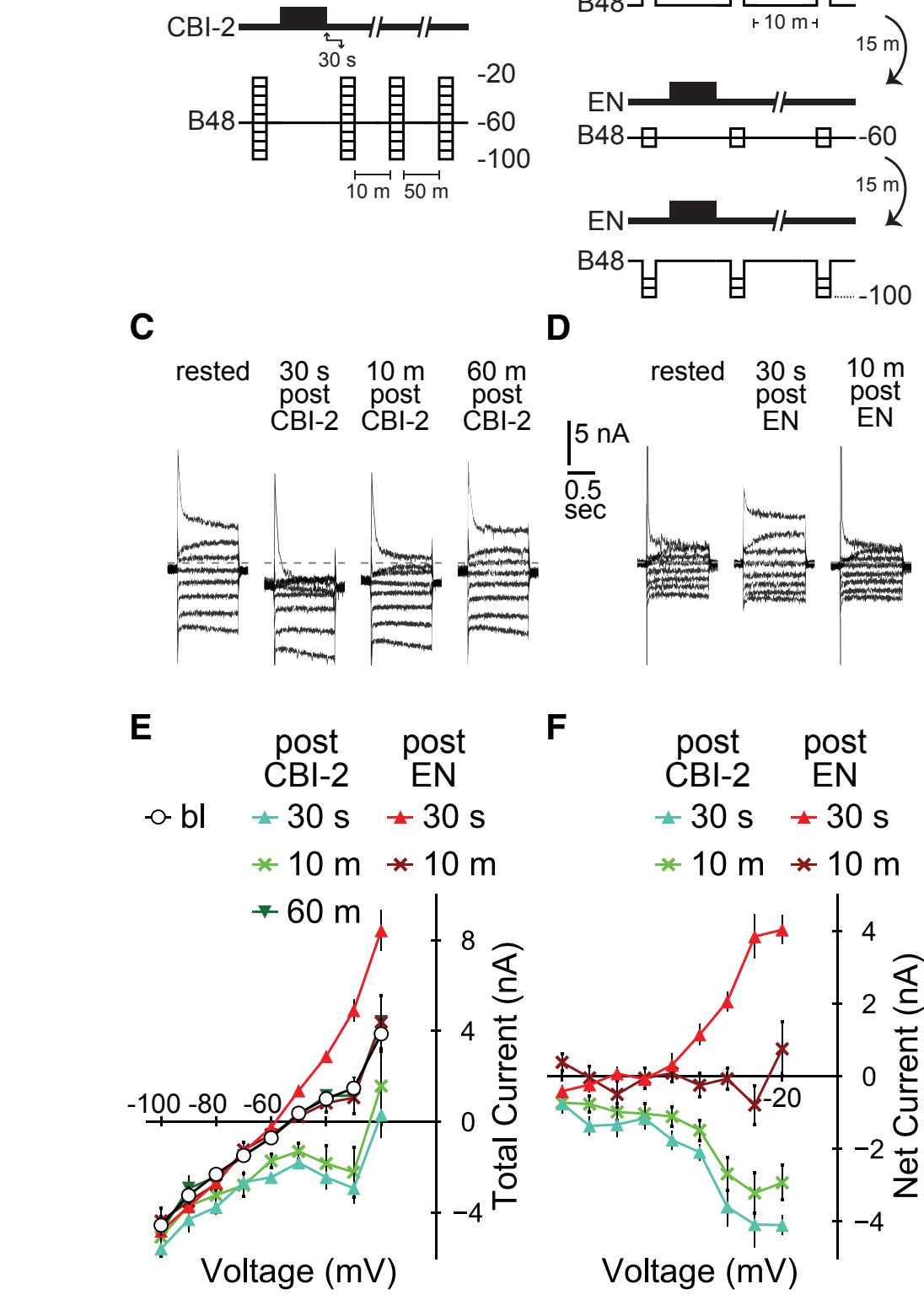

Figure 5. CBI-2 priming and EN stimulation modulate currents with different biophysical properties in B48. A, Paradigm used for experiments that characterized the inward current induced by ingestive priming. B48 was voltage-clamped, and its steady-state current-voltage relationship was determined by applying a series of voltage steps that ranged from -100 to $-20 \mathrm{mV}$ in $10 \mathrm{mV}$ increments. Steps were delivered before and after ingestive priming (10 cycles of CBI- 2 induced motor activity). $\boldsymbol{B}$, Paradigm used for experiments that characterized the outward current induced by egestive priming. B48 was voltage-clamped, and its steady-state current-voltage relationship was determined by applying steps that covered the voltage range described in $\boldsymbol{A}$. Steps were delivered before and after egestive priming ( $2 \mathrm{~min}$ of EN stimulation, $\sim 5$ cycles of motor activity). Because effects of egestive priming do not last as long as effects of ingestive priming, it was not possible to deliver all voltage steps in one run. Consequently, steps were delivered three at a time, in ascending or descending order. Preparations were rested for 15 min between runs. C, Example traces of total currents measured in B48 at rest and at $30 \mathrm{~s}$, $10 \mathrm{~min}$, and $60 \mathrm{~min}$ after 10 cycles of repeated CBI-2 stimulation. D, Example traces of total currents measured in B48 at rest, and at 30 s and 10 min after repeated EN stimulation. $\boldsymbol{E}$, Aggregate data $(N=5)$ of B48 steady-state current-voltage relationship at rest, and at indicated times following either repeated CBI-2 stimulation or EN stimulation. The steady-state IV was constructed by plotting the average current over the last $100 \mathrm{~ms}$ of each step against the command voltage. $F$, Net currents activated by input stimulation were measured by calculating difference currents. For each voltage step, the baseline steady-state holding current was subtracted from the holding current measured at the indicated time after stimulating either EN (squares) or CBI-2 (diamonds) $(N=5)$. 
citability decreases are observed, and $10 \mathrm{~min}$, when excitability decreases are no longer observed. Based on our measurement of EN's effect on B48 excitability (Fig. 3), we expected any current activated by EN stimulation to diminish appreciably over the period of time required to complete the entire voltage step protocol. To minimize the effect of this complication, the step protocol was divided into three portions, and each portion was separated by $\sim 15$ min (Fig. $5 B$, paradigm). The effect of EN stimulation completely dissipated during the $15 \mathrm{~min}$ period between portions, so the effects evoked by each stimulation should be comparable with previous figures. The order of applied voltage steps (i.e., ascending vs descending) was alternated across preparations. EN-induced currents were calculated by subtracting currents induced after 2 min of EN stimulation from those measured before (Fig. 5F, red data). We found that EN stimulation induced a net outward current that was voltage-dependent (oneway ANOVA, $N=7, F_{(8,54)}=27.41$; Fig. $\left.5 D\right)$. The net current at $-60 \mathrm{mV}$ was $0.31 \pm 0.33 \mathrm{nA}$, whereas the net current at $-30 \mathrm{mV}$ was $3.85 \pm 0.61 \mathrm{nA}\left(N=7, t_{(6)}=7.57, p<0.001\right)$. This current changed significantly with time after stimulation (two-way ANOVA; $\left.F_{(1,8)}=36.21, p<0.001\right)$. For example, at $10 \mathrm{~min}$, the EN current was not significantly different from zero both at the holding potential $\left(-0.16 \pm 0.20 \mathrm{nA} ; N=5, t_{(4)}=-0.8, p=0.47\right)$ and at steps to $-30 \mathrm{mV}\left(-0.09 \pm 0.13 \mathrm{nA} ; N=5, t_{(4)}=-0.7\right.$, $p=0.52$ ). This time course parallels the decrease in excitability and firing frequency observed after egestive priming. These data indicate that the net current induced by EN stimulation is outward.

However, a net outward current could in principle be mediated by a reduction of an inward current. This seems unlikely, as the current induced by ingestive priming did not reverse, whereas the current induced by EN stimulation did. The EN current reversed at $\sim-80 \mathrm{mV}$ and became an inward current at $-100 \mathrm{mV}$ (Fig. 5D). To more precisely measure the reversal potential of the EN induced current, we applied voltage ramps from -120 to -20 $\mathrm{mV}$ (data not shown). As in experiments using a step protocol, ramps were applied in rested preparations and $30 \mathrm{~s}$ and $10 \mathrm{~min}$ after EN stimulation. The average reversal potential measured in these experiments was $-86 \pm 5.7 \mathrm{mV}(N=6)$. These data are consistent with the idea that ingestive and egestive priming modify two different currents.

Currents induced by ingestive and egestive priming are pharmacologically distinct

To further distinguish between EN and CBI-2 induced currents, we tested their sensitivity to Rp-cAMP, which blocks excitability increases induced by ingestive repetition priming (Friedman and Weiss, 2010). To determine whether induction of the persistent inward current was similarly affected, we briefly impaled B48 with a third microelectrode filled with Rp-cAMP and iontophoretically injected Rp-cAMP. Control cells were briefly impaled with a third microelectrode filled with the normal filling solution and iontophoretically loaded. Shortly after loading, the third electrode was withdrawn. Next, voltage clamp steps were performed to determine the steady state current-voltage relationship of B48 before CBI-2 stimulation. Finally, $30 \mathrm{~s}$ after completing 10 cycles of CBI-2 stimulation (i.e., when the effects of stimulation are most apparent), the voltage clamp steps were performed again to observe how the current-voltage relationship had changed. Injection of Rp-cAMP did indeed reduce current induction $\left(F_{(1,68)}=97.2, p<0.001, N=4\right)$ (Fig. $6 \mathrm{Al}$ vs Fig. $6 A 2-A 4)$. For example, when we stepped to $-20 \mathrm{mV}$, CBI-2 stimulation induced an inward current of $-3.1 \pm 0.46 \mathrm{nA}$ in control cells and a current of $0.14 \pm 0.53 \mathrm{nA}$ in RP-cAMP-loaded neurons $\left(N=4, t_{(6)}=4.57, p=0.004\right)$.

To determine whether Rp-cAMP loading blocks the outward current induced by egestive priming, we performed similar experiments but repeatedly stimulated the EN. Iontophoretic loading of Rp-cAMP and the control was performed as described above. After loading, a series of voltage clamp steps was applied to determine the cell's current-voltage relationship before EN stimulation, and then applied again $30 \mathrm{~s}$ after completing 2 min of EN stimulation. As in the previous figure, the step protocol was divided into three portions, and each portion was separated by $\sim 15$ min. Current induction was not affected $\left(F_{(1,104)}=0.3, p=0.58\right.$, $N=6$; Fig. $6 B 1$ vs Fig. $6 B 2-B 4$ ). For example, when we stepped to $-20 \mathrm{mV}, 3.28 \pm 0.52 \mathrm{nA}$ was induced in Rp-cAMP-loaded neurons and $3.0 \pm 0.6 \mathrm{nA}$ of current was induced in control neurons $\left(N=6, t_{(11)}=0.33, p=0.746\right)$. These data demonstrate that ingestive priming and egestive priming impact two distinct currents.

\section{The persistent inward current induced by stimulation of CBI-2 is responsible for excitability increases in B48}

A further question is whether modulation of the currents characterized is responsible for changes in B48 activity during priming. We initially addressed this question by using dynamic clamp techniques to introduce the inward current into unmodulated B48 neurons to determine whether the excitability increase observed would be similar to the increase induced by stimulating CBI-2. More specifically, we measured the B48 current frequency relationship under three different conditions: in rested preparations (Fig. 7A1), in rested preparations with dynamic clamp current addition (Fig. 7A2), and after ingestive priming (Fig. 7A3). Dynamic clamp introduction of the persistent inward current did change the current frequency relationship (Fig. 7A4). The slope increased: it went from $0.82 \mathrm{~Hz} / \mathrm{nA}$ to $5.35 \mathrm{~Hz} / \mathrm{nA}$. This change was comparable with the change observed after ingestive priming $\left(t_{(5)}=0.24, p=0.81\right)$. After priming, the slope was $5.84 \mathrm{~Hz} / \mathrm{nA}$. These data indicate that introduction of the characterized inward current can, by itself, substantially mimic the increase in B48 excitability observed after priming.

To determine how dependent our results were on the specific parameters used to model the injected current, we conducted experiments in which we reduced $g_{\max }$ so that it was $80 \%$ of the original value. This did not have a significant effect on the outcome of the experiment. The slope of the current frequency plot was increased to $4.05 \mathrm{~Hz} / \mathrm{nA}$, which was not significantly different from the original slope $\left(N=3, t_{(5)}=-1.82, p=0.425\right.$; Fig. $7 A 4)$. This suggests that the effect of introducing the CBI-2 elicited current using the dynamic clamp method is robust and not overly sensitive to individual parameters of the modeled current.

\section{The persistent outward current induced by EN stimulation is responsible for excitability decreases in $\mathrm{B} 48$}

In a second set of excitability experiments, we used dynamic clamp techniques to introduce the characterized outward current to determine whether excitability decreases would be similar to those observed after egestive priming. Thus, B48's current frequency relationship was measured in rested preparations (Fig. $7 B 1$ ), in rested preparations with dynamic clamp current addition (Fig. 7B2), and after repeated EN stimulation (Fig. 7B3). Dynamic clamp current addition produced a significant decrease in the slope of the current frequency relationship. The slope was $1.76 \mathrm{~Hz} / \mathrm{nA}$ in control preparations, and was $0.73 \mathrm{~Hz} / \mathrm{nA}$ when the outward current was added $\left(t_{(5)}=5.7, p=0.002\right)$. Further, 
the slope of the current frequency relationship observed with dynamic clamp addition of the EN current was not significantly different from that observed after EN priming $(0.73 \mathrm{~Hz} / \mathrm{nA}$ vs $0.44 \mathrm{~Hz} / \mathrm{nA})$ $\left(t_{(5)}=1.53, p=0.65\right)$. Again, this effect was robust in that the introduction of $80 \%$ of the current's $g_{\max }$ resulted in a slope of $0.74 \mathrm{~Hz} / \mathrm{nA}$, which was not significantly different from the slope observed with the full $g_{\max }\left(t_{(5)}=0.028, p=0.97\right)$. These data indicate that introduction of the characterized outward current can substantially mimic decreases in excitability observed after egestive priming.

\section{The persistent current induced by ingestive priming is responsible for changes in the B48 firing frequency during motor programs}

A further question is whether changes in excitability that result from dynamic clamp introduction of characterized currents will be sufficient to modify the B48 firing frequency during motor programs. This question was initially addressed by introducing the persistent inward current into unmodulated neurons. More specifically, we triggered three cycles of motor activity using a long $(15 \mathrm{~m})$ ICI so that repetition priming would not occur (Fig. $8 A 1)$. The dynamic clamp was off during the first cycle (Fig. 8A1, Pre Clamp Control), on during the second cycle (Fig. $8 A 1$, With Dynamic Clamp), and off during the third cycle (Fig. 8A1, Post Clamp Control). To be able to directly compare effects of dynamic clamp current addition to effects of repetition priming we performed one additional manipulation. After the postclamp control we repeatedly stimulated CBI-2 so that 10 cycles of motor activity were triggered with a short (30 s) ICI. We then measured the B48 firing frequency during the last cycle (Fig. $8 A 1$, After Priming).

The B48 firing frequency under the four conditions did indeed differ $\left(F_{(3,23)}=\right.$ 30.78, $N=6, p<0.001$; Fig. $8 A 2, A 3)$. The mean frequency during the preclamp control was $2.34 \pm 0.29 \mathrm{~Hz}$. Dynamic clamp addition of the inward current significantly increased the frequency to $6.14 \pm$ $0.38 \mathrm{~Hz}\left(t_{(11)}=6.77, p<0.001\right)$. The mean frequency during the postclamp control was $2.69 \pm 0.67 \mathrm{~Hz}$, which was not significantly different from the frequency during the preclamp control $\left(t_{(11)}=0.58, p=0.56\right)$. After ingestive priming, the frequency increased to $7.06 \pm 0.52 \mathrm{~Hz}$, which was not significantly different from the frequency observed when the dynamic clamp was used to introduce the inward current $\left(t_{(11)}=\right.$ $1.37, p=0.37)$. These data indicate that dynamic clamp introduction of the persistent inward current can, by itself, mimic

A3

A4

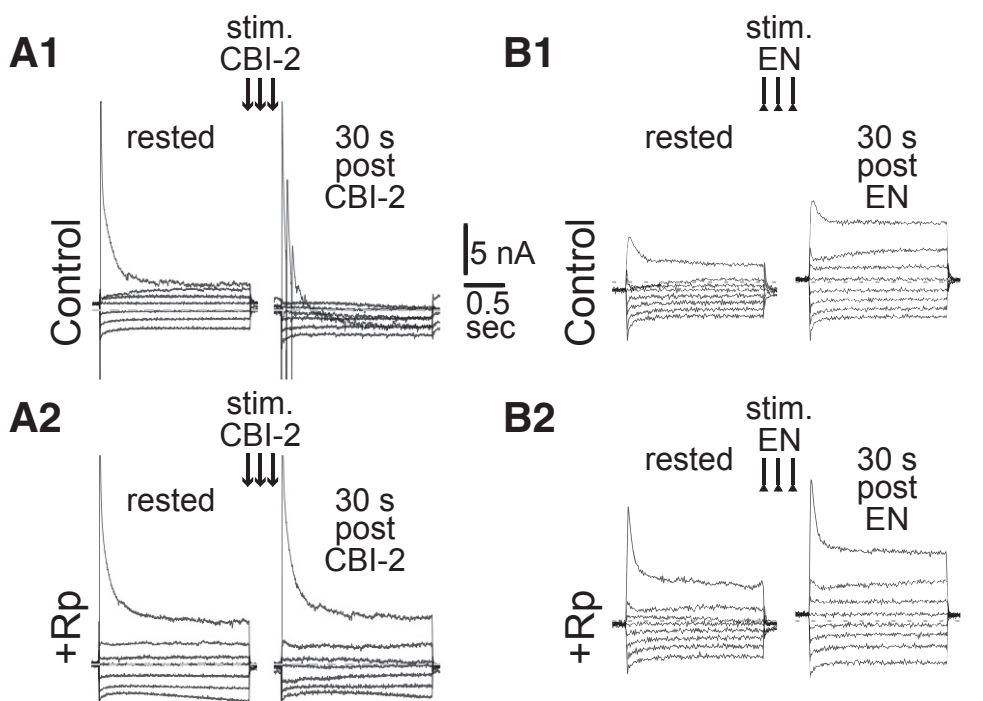

B3

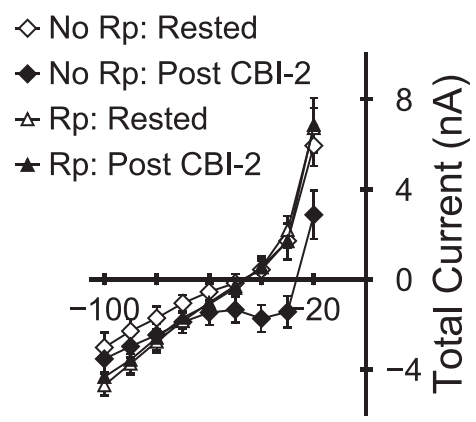

o- No Rp: Rested

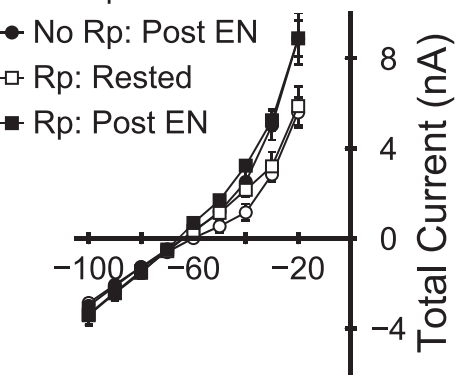

B4
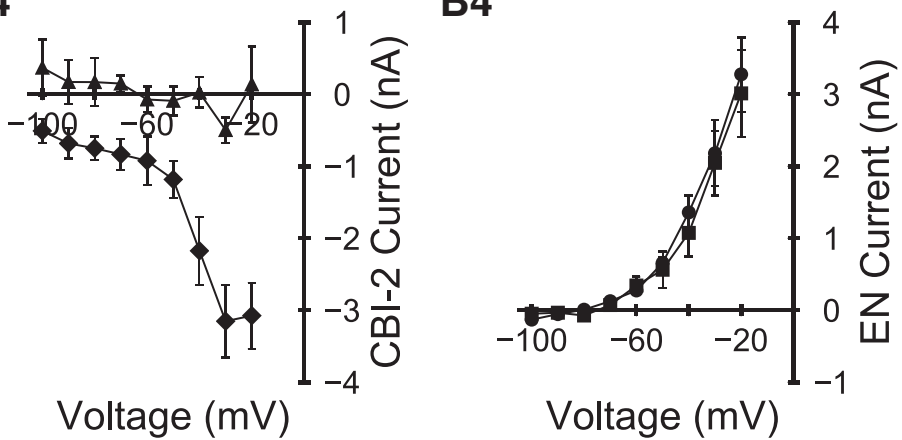

Figure 6. Rp-CAMP blocks the inward CBI-2-activated current in B48, but not the outward EN activated current. $A$, Rp-CAMP blocks the (BI-2 current. Example traces showing repeated (BI-2 stimulation (10 cycles, 30 s interstimulus interval) elicits an inward current in control B48 cells ( $\boldsymbol{A}$ 1), which is blocked by preloading with Rp-CAMP $(\boldsymbol{A} 2)$. Aggregate data $(N=4)$, showing B48 current-voltage relationship before and after $\mathrm{CBI}-2$ stimulation, in control cells, and those loaded with Rp-cAMP (A3). The net inward current elicited by repeated CBI-2 stimulation was blocked by loading B48 with Rp-CAMP, but not with the loading control (A4). Net currents were obtained by subtracting the steady-state holding current at rest from that measured after CBI-2 stimulation, for each voltage step. $\boldsymbol{B}, \mathrm{Rp}$-cAMP does not block the EN current. Example traces showing repeated EN stimulation ( $2 \mathrm{~min} \sim 5$ cycles; for paradigm, see Fig. 5B) elicit an outward current in control B48 cells (B1), which is not blocked by loading with Rp-cAMP (B2). Aggregate data $(N=6)$, showing the $B 48$ current-voltage relationship before and after EN stimulation, in control cells, and those loaded with Rp-cAMP (B3). The net outward current elicited by repeated EN stimulation is not affected by Rp-cAMP $(\boldsymbol{B} 4)$.

the frequency increase observed in B48 during ingestive priming.

In a second set of experiments, we used the dynamic clamp to inject the inverse of the persistent current into neurons that had been modulated during ingestive repetition priming. Injecting the inverse of a current in effect "subtracts" or "cancels" it. Thus, we sought to determine whether dynamic clamp current 


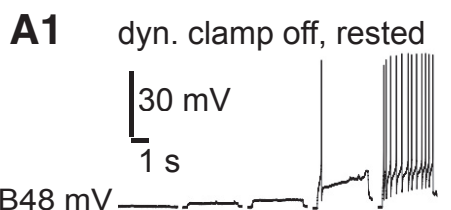

A2 dyn. clamp on, rested

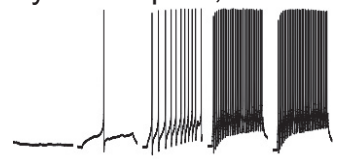

A3

dyn. clamp off

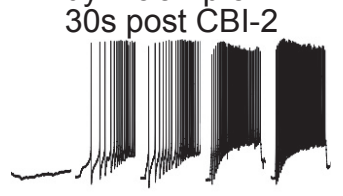

B48 nA

$12 \mathrm{nA}$
B1

dyn. clamp off, rested

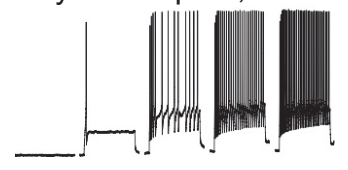

B2

dyn. clamp on, rested

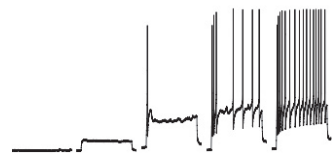

B3 dyn. clamp off, 30s post EN

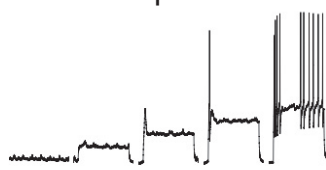

B48 nA

B4

A4

ㅁ. Dyn Off, Rested

ㅁ. Dyn CBI-2 Curr. 80\%

$\square$ Dyn CBI-2 Curr. 100\%

$\star$ Dyn Off, 30s Post CBI-2

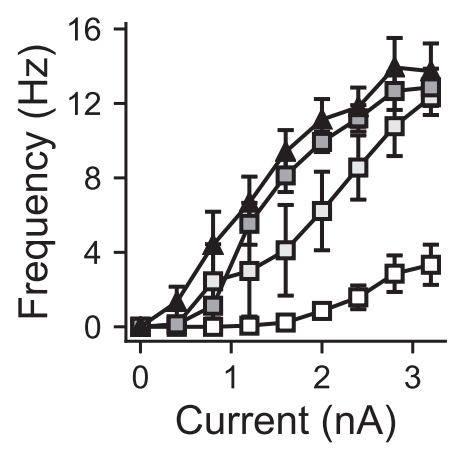

ㅁ. Dyn Off, Rested

口. Dyn EN Curr. 80\%

口 Dyn EN Curr. 100\%

- Dyn Off, 30s Post EN

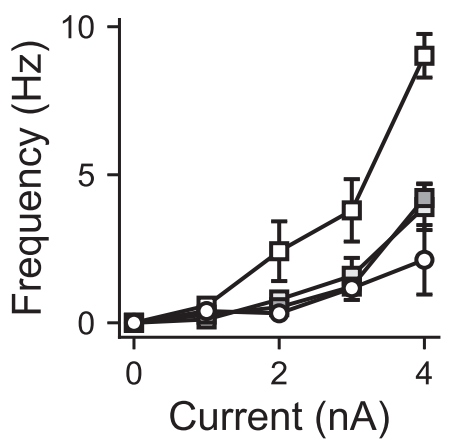

Figure 7. Induction of persistent currents modifies the frequency current (f-I) relationship in B48. $A$, Induction of the inward current increases the slope of the $\mathrm{f}-\mathrm{I}$ plot. The $\mathrm{f}-\mathrm{I}$ relationship was determined (1) in rested preparations (A1), (2) in rested preparations with dynamic clamp addition of the inward current at $100 \% g_{\max }(\boldsymbol{A 2})$, and (3) 30 s after repeated CBI-2 stimulation (10 cycles, 30 s interstimulus interval) (A3). A4, Group data are plotted along with data obtained with dynamic clamp addition of the inward current at $80 \% g_{\max }$ Effects of dynamic clamp current addition and ingestive priming are similar: both increased the slope of the $\mathrm{f}-\mathrm{I}$ plot $(N=6)$. $\boldsymbol{B}$, Induction of the outward current decreases the slope of the $\mathrm{f}-\mathrm{I}$ plot. The $\mathrm{f}-\mathrm{I}$ relationship was determined (1) in rested preparations (B1), (2) in rested preparations with dynamic clamp addition of the outward current at $100 \%$ $g_{\max }(B 2)$, and (3) $30 \mathrm{~s}$ after repeated EN stimulation (2 $\mathrm{min} \sim 5$ cycles) (B3). B4, Group data are along with data obtained with dynamic clamp addition of the inward current at $80 \% g_{\max }$. Effects of dynamic clamp current addition and egestive priming are similar: both decreased the slope of the f-I plot $(N=6)$.

subtraction would return activity to control (before priming) levels. To induce priming, we elicited 10 cycles of motor activity by stimulating CBI-2 with a $30 \mathrm{~s}$ ICI (Fig. 8B1). To verify that priming had occurred, we measured the B48 firing frequency during the 10th cycle (Fig. 8 B1, Pre Clamp). We then triggered an 11th cycle and used the dynamic clamp for current subtraction (Fig. 8B1, Subtract Dyn). Finally, we elicited a 12th cycle with the dynamic clamp off (Fig. 8B1, Post Clamp).
The B48 firing frequency under the four conditions varied $\left(F_{(3,22)}=70.13\right.$, $p<0.001, N=6$ ). We found that priming increased the B48 firing frequency so that it went from $2.21 \pm 0.18 \mathrm{~Hz}$ to $7.25 \pm 0.47$ $\mathrm{Hz}$ (Fig. 8B2,B3; $t_{(5)}=12.5, p<0.001$ ). Dynamic clamp subtraction of the persistent inward current produced a significant decrease in firing frequency: it went to $3.46 \pm 0.36 \mathrm{~Hz}$ (Fig. $8 B 2, B 3 ; t_{(5)}=$ $-8.54, p<0.001)$. Interestingly, however, this does not represent a return to the control (before priming) frequency $\left(t_{(5)}=\right.$ $2.62, p=0.047)$. Presumably, this is due to the fact that increases in synaptic current contribute, albeit to a much lesser degree, to changes in the B48 firing frequency during motor programs. The reduction in frequency did reverse once the dynamic clamp was turned off. The B48 firing frequency went to $7.22 \pm 0.18 \mathrm{~Hz}$, which was not significantly different from the postpriming frequency before current subtraction (Fig. $8 B 2, B 3 ; t_{(5)}=-0.24$, $p=0.81)$. These data indicate that induction of the persistent inward current plays a major role in determining the firing frequency of B48 during ingestive repetition priming.

The persistent outward current induced by stimulating the EN reduces the $\mathrm{B} 48$ firing frequency during task-switches When the EN is stimulated after ingestive priming, there is a decrease in the firing frequency of B48 (Fig. 4A1,A3). To determine whether this decrease results from the induction of the characterized outward current, we performed experiments in which we used dynamic clamp techniques to manipulate it. These experiments took advantage of the fact that there are two B48 neurons. In one set of experiments, we used the dynamic clamp to subtract the outward current from one neuron. The contralateral neuron served as a control: we recorded from it but did not manipulate it (Fig. 9A1). For both B48 neurons, we computed the average B48 firing frequency before ingestive priming, after ingestive priming, and after EN stimulation (i.e., after the task-switch). There was a difference between the two datasets $\left(F_{(1,25)}=5.07, N=7, p=0.03\right)$ (Fig. $9 A 2, A 3)$. In control cells (no dynamic clamp manipulation), EN stimulation produced a significant reduction in firing frequency $\left(t_{(6)}=-6.51, p=0.002\right)$. The firing frequency was $7.68 \pm 0.40$ $\mathrm{Hz}$ after priming and $3.99 \pm 0.46 \mathrm{~Hz}$ after EN stimulation. In contrast, when dynamic clamp techniques were used to subtract the EN-induced current at $100 \% g_{\max }$, firing frequency did not decrease $\left(t_{(6)}=-2.07, p=0.11\right)$. After priming, the frequency was $6.82 \pm 0.48 \mathrm{~Hz}$; and after EN stimulation with current subtraction, it was $7.42 \pm 0.40 \mathrm{~Hz}$. Similar results were 

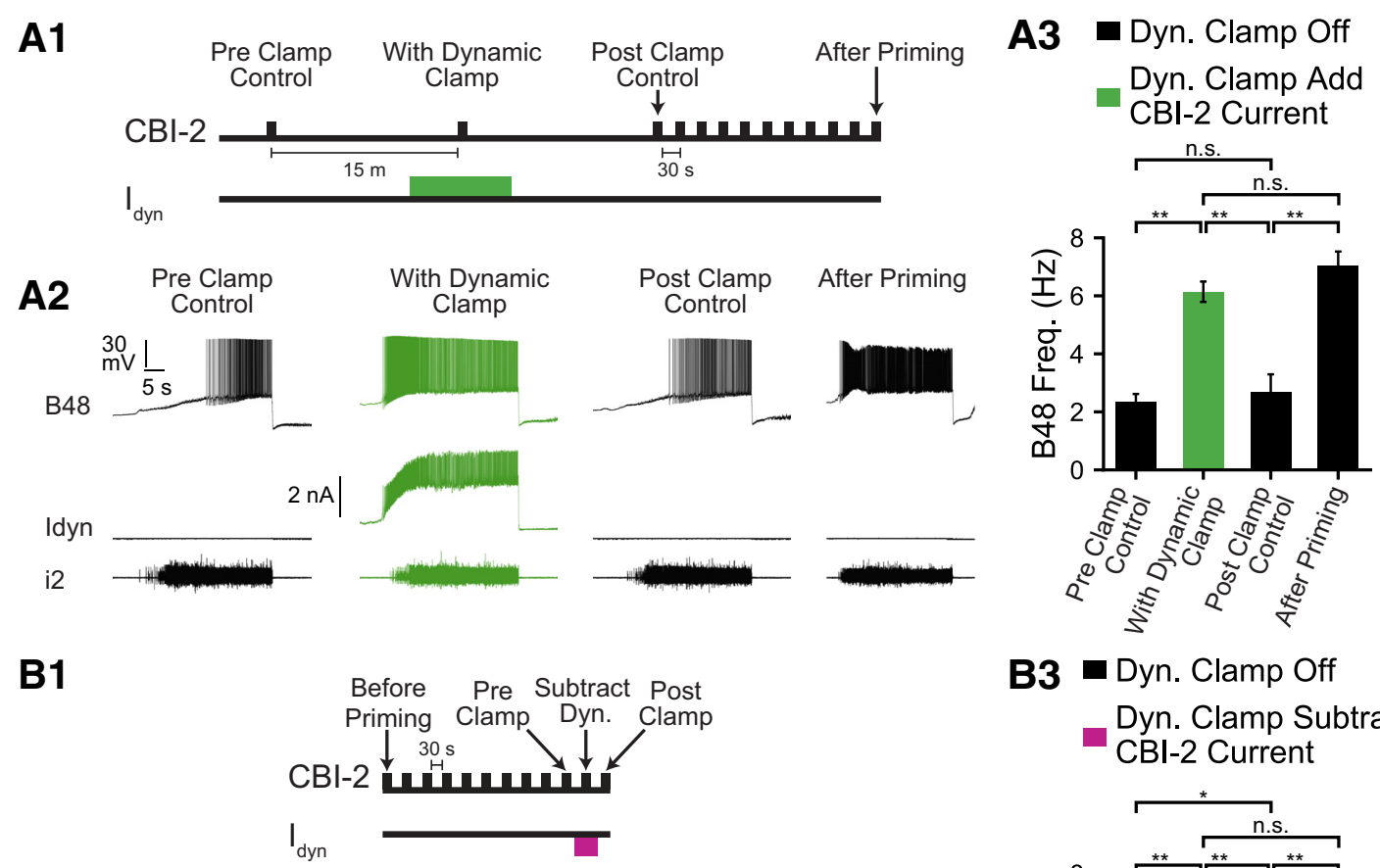

B2

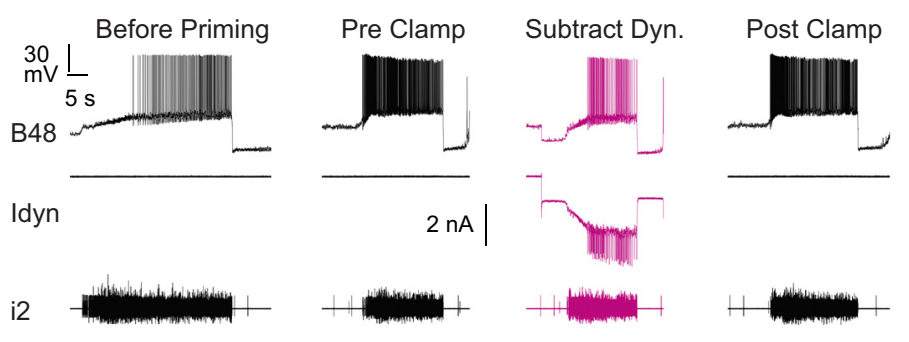

\section{B3 Dyn. Clamp Off \\ Dyn. Clamp Subtract CBI-2 Current}

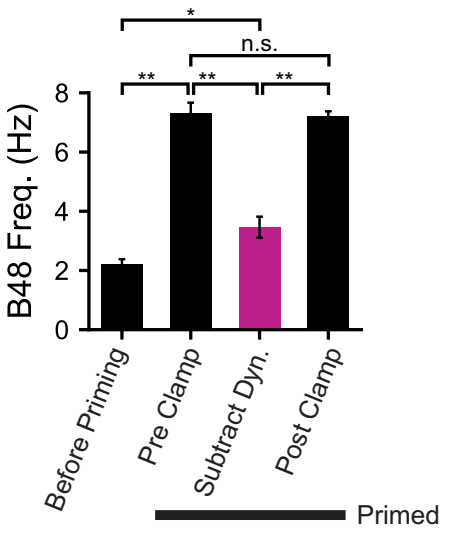

Figure 8. The persistent current induced by ingestive priming is responsible for changes in the B48 firing frequency during motor programs. $A$, Dynamic clamp addition of the inward current increases the B48 firing frequency during motor programs. A1, Experimental paradigm. Green represents the period of time when the inward current was added. $\boldsymbol{A 2}$, Top, Intracellular current-clamp recording from B48. Middle, Current injected into B48 by the dynamic clamp $\left(I_{\text {dyn }}\right)$. Bottom, Extracellular recording from the i2 nerve (i2). Traces in green represent the dynamic clamp current added. A3, Aggregate data. Green represents data obtained with the addition of the dynamic clamp. The B48 firing frequency was increased by current-clamp addition of the inward current and by ingestive priming $(N=6) .{ }^{* *} p<0.01$. B Dynamic clamp subtraction of the inward current decreases the B48 firing frequency during motor programs. $B$, Experimental paradigm. Pink represents the period of time when the inward current was subtracted. B2, Top, Intracellular current-clamp recording from B48. Middle, Current injected into B48 by the dynamic clamp $\left(I_{\text {dyn }}\right)$. Bottom, Extracellular recording from the $\mathrm{i} 2$ nerve (i2). Traces in pink represent the dynamic clamp current subtracted. $\boldsymbol{B}$ 3, Aggregate data. Pink represents data obtained with the subtraction of the dynamic clamp. The B48 firing frequency was decreased by current-clamp subtraction of the inward current $(N=6) .{ }^{*} p<0.05,{ }^{* *} p<0.01$.

obtained when the EN-induced current was subtracted at $80 \%$ $g_{\text {max }}\left(t_{(8)}=-0.85, p=0.8, N=4\right.$ or 5 ) (data not shown). In this situation, B48 fired at $6.39 \pm 0.42 \mathrm{~Hz}$. This suggests that the induced outward current is necessary for the suppression of B48 activity that is observed after EN stimulation.

In a second set of experiments, we induced ingestive priming but did not perform the task-switch (i.e., stimulate the EN) (Fig. 9B1). Instead, we attempted to reduce firing frequency by using the dynamic clamp to add the outward current to one B48 neuron. Again, the other B48 was not manipulated and served as a control. We determined the average B48 firing frequency before ingestive priming, after ingestive priming, and after dynamic clamp current addition. In this situation, there was also a significant difference between the two datasets $\left(F_{(1,25)}=15.52, N=6, p=0.0006\right)$ (Fig. 9B2,B3). Dynamic clamp addition of the outward current significantly reduced firing frequency $\left(t_{(5)}=-8.99, p=0.002\right)$. Thus, the frequency after priming but before current addition was $7.45 \pm 0.17 \mathrm{~Hz}$. With current addition at $100 \% g_{\max }$, the frequency dropped to
$4.33 \pm 0.28 \mathrm{~Hz}$, making it essentially the same as the firing frequency before ingestive priming $\left(t_{(5)}=1.22, p=0.29\right)$. With current addition at $80 \% g_{\max }$, the frequency dropped to a similar value $\left(4.85 \pm 0.36 \mathrm{~Hz} ; t_{(5)}=-2.2, p=0.06\right)$. In contrast, when firing frequency was measured in the control B48 at matched time points, there was no significant decrease $\left(t_{(5)}=1.21, p=0.28\right)$. The frequency immediately after priming was $7.68 \pm 0.23 \mathrm{~Hz}$. The frequency after 2 min was $7.48 \pm$ $0.21 \mathrm{~Hz}$. Together, these data indicate that induction of the outward current is both necessary and sufficient for firing frequency decreases observed in the task-switch paradigm.

\section{Discussion}

Our experiments are conducted in a network that receives modulatory input that configures motor activity. When this network is modulated, it enters a state in which it is biased to generate one type of motor program as opposed to another (Proekt et al., 2004, 2007; Friedman and Weiss, 2010; Dacks et al., 2012; Dacks and Weiss, 2013; Friedman et al., 2015; Siniscalchi et al., 2016). States 

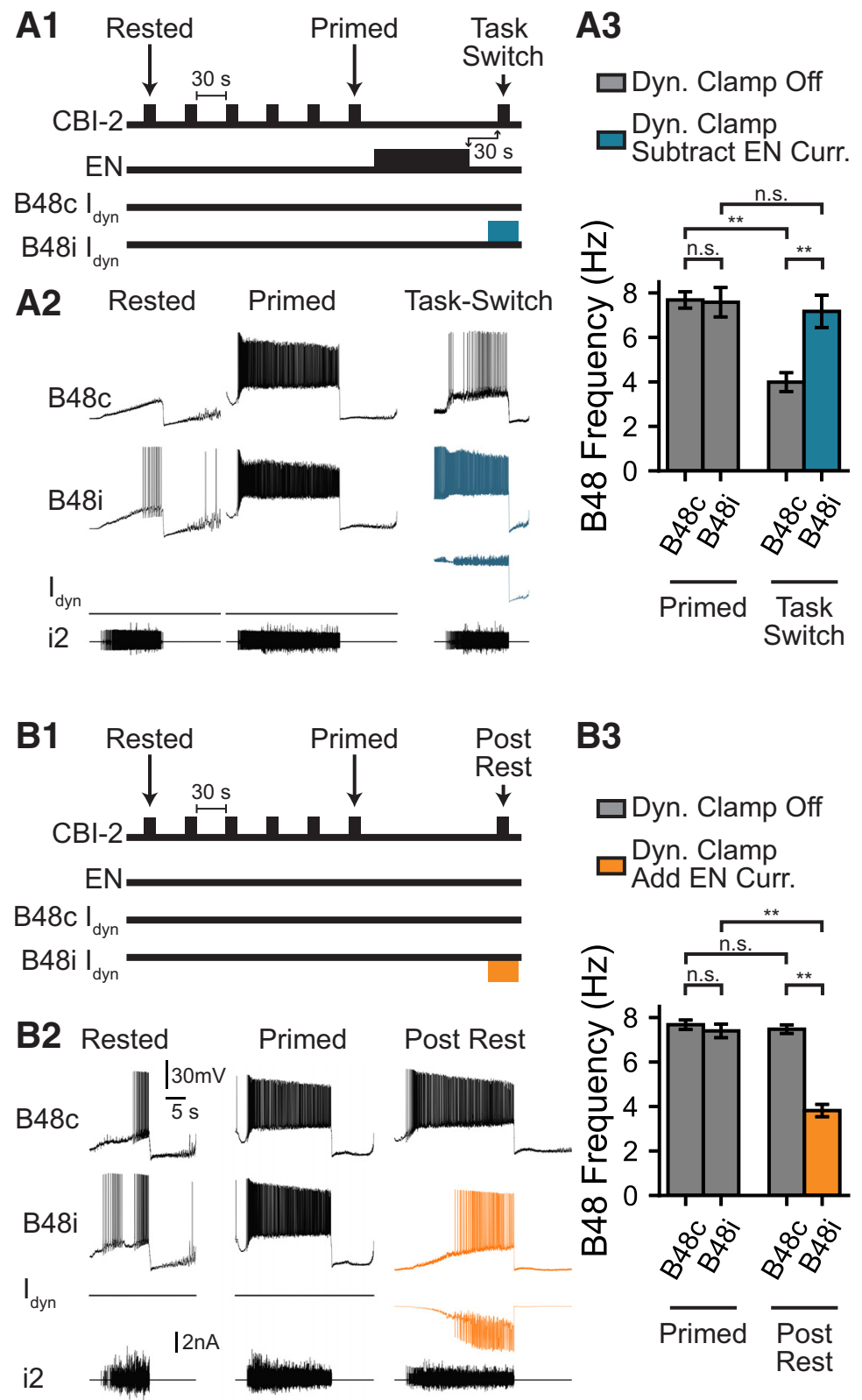

Figure 9. Dynamic clamp manipulation of the outward current alters the B48 firing frequency during motor programs. $A$, Dynamic clamp subtraction of the outward current after a task-switch. A1, Experimental protocol. A2, Top two traces represent intracellular current-clamp recordings from the two B48 neurons. Third trace represents the dynamic clamp current injected into the B48i $\left(I_{d y n}\right)$. Bottom, Extracellular recording from the i2 nerve (i2). After the switch, there is a decrease in the firing frequency of the neuron that was not subjected to the dynamic clamp current subtraction (B48c). In contrast, there is no firing frequency decrease when the outward current was subtracted (B48i). $\boldsymbol{A} \mathbf{3}$, Group data $(N=7)$. $\boldsymbol{B}$, Dynamic clamp addition of the outward current when there is no task-switch. $\boldsymbol{B}$, Experimental protocol. $\boldsymbol{B 2}$, Top two traces represent intracellular current-clamp recordings from the two B48 neurons. Third trace represents the dynamic clamp current injected into B48i $\left(I_{\text {dyn }}\right)$. Bottom, Extracellular recording from the $i 2$ nerve (i2). There was a decrease in the firing frequency of the neuron that was subjected to the dynamic clamp current addition (B48i). In contrast, there was no firing frequency decrease at the same time point in the control neuron (B48c). B3, Group data $(N=6) .{ }^{* *} p<0.01$.

persist for at least $10 \mathrm{~min}$. A question we addressed in this study is as follows: how will this impact the ability of the network to switch from one motor program to another (task-switch)? We focus on switches between ingestion and egestion. Ingestive/egestive switches can occur when an animal eats a piece of seaweed that cannot be pulled into the buccal cavity (e.g., it is attached to a rock). In this situation, Aplysia can stop generating ingestive responses, egest the attached seaweed, and then return to ingestion (Proekt et al., 2008).
When Aplysia task-switch, there are phase changes in the activity of the motor neurons that open and close the radula (Morton and Chiel, 1993a,b). This study focuses on opening. Other experiments have studied the reconfiguration of activity in the closer circuitry (e.g., Proekt et al., 2004, 2007; Dacks et al., 2012). Previously, we demonstrated that, when the ingestive state is induced, there are progressive increases in the firing frequency of the radula opener motor neuron B48 (Friedman et al., 2009; Friedman and Weiss, 2010). Increases in firing frequency are correlated with a peptide-mediated increase in excitability (Friedman and Weiss, 2010). This study sought to determine whether the excitability increase is the major determinant of the firing frequency change. Together, our data indicate that this is the case. Further, we sought to determine how the excitability increase is mediated. We demonstrate that it results from the induction of a persistent inward current.

The identification of a specific locus of plasticity responsible for ingestive priming allowed us to pose a further question: what happens to it when the network is forced to generate egestive activity? In general terms, a switch to egestive activity could "erase" the ingestive state. In B48, this would presumably be mediated by a reduction or elimination of the inward current induced during ingestive priming. Alternatively, the induction of egestive activity could simply "suppress" the ingestive state. Suppression would presumably be mediated by the induction of an outward current (rather than a decrease in the magnitude of the inward current). The two types of models potentially have important consequences for a subsequent return to ingestion. If egestive activity erased the ingestive state, it would not be possible to immediately return to ingestive behavior. For ingestion to be reinitiated, priming would be necessary. In contrast, if egestive activity merely suppressed the ingestive state, an immediate return to ingestion would be possible. Thus, the dynamics of task-switching would differ in the two situations.

We demonstrate that egestive priming induces an outward current. When this outward current is induced "on top" of ingestive priming, there is a reduction in the net inward current in B48. This decreases B48's excitability and firing frequency. Firing frequency drops to baseline (unmodulated) levels. When B48 fires at these frequencies, radula opening is very weak (Friedman et al., 2009). Radula movements are therefore altered in a manner that is necessary for a switch to egestion. It is likely that effects of egestive priming are like those of ingestive priming in that they are second messengermediated. Effects of egestive priming persist (i.e., last for min- 
utes). It is highly unlikely, however, that the same modulator(s) is involved. Neither FCAP or CP2 is released by EN stimulation (Jing et al., 2007). Further, several lines of data have strongly suggested that a form of chemical coding is used in the feeding circuit in that one set of modulatory neurotransmitters promotes ingestive activity and a second set promotes egestive activity. Modulators that promote egestive activity include SCPb, the RFamide peptides, and aNPY, all of which are released by EN stimulation and induce an egestive configuration of motor activity (Morgan et al., 2002; Jing et al., 2007; Vilim et al., 2010). SCPb activates PKC in another radula opener motor neuron, B44 (Friedman et al., 2015). The involvement of a different second messenger could explain the difference between the persistence of the ingestive and egestive currents, as different second messenger systems often have different inherent dynamics (Goaillard et al., 2001; Willoughby and Cooper, 2006; Zhang et al., 2011).

The fact that egestive priming induces a distinct current does not in itself indicate that the ingestive state has been "retained." However, data obtained in ingestive-egestive task-switch experiments indicate that this is the case. For example, if the inverse of the egestive current is injected into B48 after the switch to egestive activity, the B48 firing frequency is above baseline levels and is similar to the firing frequency observed at a matched time point when ingestive priming is not followed by egestion. This indicates that the induction of egestive activity did not erase effects of the original ingestive priming. To put our results in general terms, we characterize a mechanism that allows the retention of one type of network state during a task-switch that involves the induction of an incompatible motor program.

\section{Regulation of excitability in other systems}

The type of circuit modification that we study is a regulation of excitability. Although a number of studies of circuit plasticity have focused on mechanisms that alter synaptic strength, it is becoming increasingly apparent that the regulation of excitability can be equally important (Benjamin et al., 2008; Mozzachiodi and Byrne, 2010). In our system, ingestive and egestive priming has a "bidirectional" effect on excitability (ingestive priming increases it and egestive priming decreases it). Bidirectional changes in excitability have been observed in other very different contexts (e.g., in the context of fear conditioning) (Santini et al., 2008; Santini and Porter, 2010). In some situations, a single current is modified: for example, serotonin and FMRFamide have opposite effects on the excitability of Aplysia sensory neurons (Klein et al., 1982; Dale et al., 1987; Critz et al., 1991), and both alter the S current with serotonin decreasing it (Shuster et al., 1985) and FMRFamide increasing it (Belardetti et al., 1987). In contrast, we demonstrate that a similar result can be achieved via the induction of two distinct currents. As we demonstrate, an advantage of the two current model is that it makes it possible to counteract a network modification without reversing it. Excitability data suggest that the same type of regulation may occur elsewhere. For example, infralimbic excitability changes induced during fear conditioning are reversed during extinction training but can then reemerge when fear responses are spontaneously expressed (Cruz et al., 2014).

\section{Task-switching in other systems}

Many neural networks dynamically switch between motor programs that mediate different behaviors. For example, switches from ingestion to egestion are observed in other species, including mammals (e.g., Dinardo and Travers, 1994). Locomotor patterns can be dynamically turned on and off so that there is a change in gait, form, or direction (e.g., Mesce and PierceShimomura, 2010; Gruhn et al., 2011; Kawano et al., 2011; Bellardita and Kiehn, 2015). The perception of danger can trigger a startle behavior that pauses or suppresses a competing motor program, such as feeding (e.g., Jing and Gillette, 1995, 2000; Pirger et al., 2014) or slow locomotion (e.g., Song et al., 2015). Most investigators who have studied task-switches in other species have focused on the cellular and synaptic mechanisms responsible for decision making. Thus, they have characterized processes that turn one motor program off and a second motor program on. From this research, it has become apparent that inhibitory interactions between competing circuits are often important in this context (e.g., Kovac and Davis, 1977; Jing and Gillette, 1995, 2000; Jovanic et al., 2016). Further, sensory-motor transmission can be selectively regulated so that effects of afferent activation are context-dependent (Gaudry and Kristan, 2009).

Our experiments differ in that they are directed at a further issue that arises in the situation where an ongoing behavior is interrupted by a relatively brief behavioral switch. We ask how a network can quickly and efficiently return to a previously established state. This issue has been addressed relatively recently in zebrafish (Song et al., 2015). Zebrafish swimming at a certain frequency can generate an escape response and then rapidly return to swimming without a change in frequency. This occurs because the premotor neurons driving the swim motor neurons remain active during the escape response. This does not have a negative impact on the escape response because the swim motor neurons are inhibited (i.e., disengaged). When the escape response is over, the swim motor neurons "reengage." In this situation, the original state is retained by maintained neural (premotor) activity.

The mechanism that we describe differs in that the retention of the original state is a consequence of the fact that it is established by neurotransmitters that exert second messengermediated effects. Consequently, modulatory effects persist long enough to "survive" a relatively brief change in motor activity. Specifically, our data indicate that persistent effects are cAMPmediated. We show that the original state is primarily mediated via the induction of a persistent inward current that is blocked by Rp-cAMP. The type of mechanism that we describe is likely to be used in other systems. Network activity is commonly configured and reconfigured by modulatory neurotransmitters (e.g., HarrisWarrick and Marder, 1991; Marder et al., 2005).

In conclusion, these experiments were conducted in an experimentally advantageous multitasking network in which it is possible to study task-switching at a cellular/molecular level. A general question we address is as follows: what will happen to a network primed to induce one type of output when it is forced to generate a functionally incompatible motor program? We show that it is possible to retain the original priming, and we demonstrate how this can be accomplished as a result of a biochemical modification rather than maintained neural activity.

\section{References}

Belardetti F, Kandel ER, Siegelbaum SA (1987) Neuronal inhibition by the peptide FMRFamide involves opening of $\mathrm{K}^{+}$channels. Nature 325:153156. CrossRef Medline

Bellardita C, Kiehn O (2015) Phenotypic characterization of speedassociated gait changes in mice reveals modular organization of locomotor networks. Curr Biol 25:1426-1436. CrossRef Medline

Benjamin PR, Kemenes G, Kemenes I (2008) Non-synaptic neuronal mechanisms of learning and memory in gastropod molluscs. Front Biosci 13: 4051-4057. Medline

Church PJ, Lloyd PE (1994) Activity of multiple identified motor neurons 
recorded intracellularly during evoked feedinglike motor programs in Aplysia. J Neurophysiol 72:1794-1809. CrossRef Medline

Critz SD, Baxter DA, Byrne JH (1991) Modulatory effects of serotonin, FMRFamide, and myomodulin on the duration of action potentials, excitability, and membrane currents in tail sensory neurons of Aplysia. J Neurophysiol 66:1912-1926. CrossRef Medline

Cropper EC, Evans CG, Hurwitz I, Jing J, Proekt A, Romero A, Rosen SC (2004) Feeding neural networks in the mollusc Aplysia. Neurosignals 13:70-86. CrossRef Medline

Cropper EC, Jing J, Perkins MH, Weiss KR (2017) Use of the Aplysia feeding network to study repetition priming of an episodic behavior. J Neurophysiol 118:1861-1870. CrossRef Medline

Cruz E, López AV, Porter JT (2014) Spontaneous recovery of fear reverses extinction-induced excitability of infralimbic neurons. PLoS One 9:e103596. CrossRef Medline

Dacks AM, Weiss KR (2013) Latent modulation: a basis for non-disruptive promotion of two incompatible behaviors by a single network state. J Neurosci 33:3786-3798. CrossRef Medline

Dacks AM, Siniscalchi MJ, Weiss KR (2012) Removal of default stateassociated inhibition during repetition priming improves response articulation. J Neurosci 32:17740-17752. CrossRef Medline

Dale N, Kandel ER, Schacher S (1987) Serotonin produces long-term changes in the excitability of Aplysia sensory neurons in culture that depend on new protein synthesis. J Neurosci 7:2232-2238. CrossRef Medline

Dinardo LA, Travers JB (1994) Hypoglossal neural activity during ingestion and rejection in the awake rat. J Neurophysiol 72:1181-1191. CrossRef Medline

Elliott CJ, Susswein AJ (2002) Comparative neuroethology of feeding control in molluscs. J Exp Biol 205:877-896. Medline

Evans CG, Rosen S, Kupfermann I, Weiss KR, Cropper EC (1996) Characterization of a radula opener neuromuscular system in Aplysia. J Neurophysiol 76:1267-1281. CrossRef Medline

Friedman AK, Weiss KR (2010) Repetition priming of motoneuronal activity in a small motor network: intercellular and intracellular signaling. J Neurosci 30:8906-8919. CrossRef Medline

Friedman AK, Zhurov Y, Ludwar BC, Weiss KR (2009) Motor outputs in a multitasking network: relative contributions of inputs and experiencedependent network states. J Neurophysiol 102:3711-3727. CrossRef Medline

Friedman AK, Weiss KR, Cropper EC (2015) Specificity of repetition priming: the role of chemical coding. J Neurosci 35:6326-6334. CrossRef Medline

Gaudry Q, Kristan WB Jr (2009) Behavioral choice by presynaptic inhibition of tactile sensory terminals. Nat Neurosci 12:1450-1457. CrossRef Medline

Getting PA (1989) Emerging principles governing the operation of neural networks. Annu Rev Neurosci 12:185-204. CrossRef Medline

Goaillard JM, Vincent PV, Fischmeister R (2001) Simultaneous measurements of intracellular cAMP and L-type $\mathrm{Ca}^{2+}$ current in single frog ventricular myocytes. J Physiol 530:79-91. CrossRef Medline

Gruhn M, Rosenbaum P, Bollhagen HP, Bueschges A (2011) Studying the neural basis of adaptive locomotor behavior in insects. J Vis Exp 50:2629. CrossRef Medline

Harris-Warrick RM, Marder E (1991) Modulation of neural networks for behavior. Annu Rev Neurosci 14:39-57. CrossRef Medline

Hurwitz I, Neustadter D, Morton DW, Chiel HJ, Susswein AJ (1996) Activity patterns of the $\mathrm{B} 31 / \mathrm{B} 32$ pattern initiators innervating the $\mathrm{I} 2$ muscle of the buccal mass during normal feeding movements in Aplysia californica. J Neurophysiol 75:1309-1326. CrossRef Medline

Jing J, Gillette R (1995) Neuronal elements that mediate escape swimming and suppress feeding behavior in the predatory sea slug pleurobranchaea. J Neurophysiol 74:1900-1910. CrossRef Medline

Jing J, Gillette R (2000) Escape swim network interneurons have diverse roles in behavioral switching and putative arousal in pleurobranchaea. J Neurophysiol 83:1346-1355. CrossRef Medline

Jing J, Weiss KR (2005) Generation of variants of a motor act in a modular and hierarchical motor network. Curr Biol 15:1712-1721. CrossRef Medline

Jing J, Vilim FS, Horn CC, Alexeeva V, Hatcher NG, Sasaki K, Yashina I, Zhurov Y, Kupfermann I, Sweedler JV, Weiss KR (2007) From hunger to satiety: reconfiguration of a feeding network by Aplysia neuropeptide Y. J Neurosci 27:3490-3502. CrossRef Medline

Jovanic T, Schneider-Mizell CM, Shao M, Masson JB, Denisov G, Fetter RD, Mensh BD, Truman JW, Cardona A, Zlatic M (2016) Competitive disinhibition mediates behavioral choice and sequences in Drosophila. Cell 167:858-870.e19. CrossRef Medline

Kawano T, Po MD, Gao S, Leung G, Ryu WS, Zhen M (2011) An imbalancing act: gap junctions reduce the backward motor circuit activity to bias $C$. elegans for forward locomotion. Neuron 72:572-586. CrossRef Medline

Klein M, Camardo J, Kandel ER (1982) Serotonin modulates a specific potassium current in the sensory neurons that show presynaptic facilitation in Aplysia. Proc Natl Acad Sci U S A 79:5713-5717. CrossRef Medline

Koh HY, Vilim FS, Jing J, Weiss KR (2003) Two neuropeptides colocalized in a command-like neuron use distinct mechanisms to enhance its fast synaptic connection. J Neurophysiol 90:2074-2079. CrossRef Medline

Kovac MP, Davis WJ (1977) Behavioral choice: neural mechanisms in pleurobranchaea. Science 198:632-634. CrossRef Medline

Kristan WB Jr, Wittenberg G, Nusbaum MP, Stern-Tomlinson W (1988) Multifunctional interneurons in behavioral circuits of the medicinal leech. Experientia 44:383-389. CrossRef Medline

Kupfermann I (1974) Feeding behavior in Aplysia: a simple system for the study of motivation. Behav Biol 10:1-26. CrossRef Medline

Marder E, Bucher D, Schulz DJ, Taylor AL (2005) Invertebrate central pattern generation moves along. Curr Biol 15:R685-R699. CrossRef Medline

Mesce KA, Pierce-Shimomura JT (2010) Shared strategies for behavioral switching: understanding how locomotor patterns are turned on and off. Front Behav Neurosci 4:49. CrossRef Medline

Morgan PT, Jing J, Vilim FS, Weiss KR (2002) Interneuronal and peptidergic control of motor pattern switching in Aplysia. J Neurophysiol 87:4961. CrossRef Medline

Morton DW, Chiel HJ (1993a) The timing of activity in motor neurons that produce radula movements distinguishes ingestion from rejection in Aplysia. J Comp Physiol A 173:519-536. Medline

Morton DW, Chiel HJ (1993b) In vivo buccal nerve activity that distinguishes ingestion from rejection can be used to predict behavioral transitions in Aplysia. J Comp Physiol A 172:17-32. CrossRef Medline

Mozzachiodi R, Byrne JH (2010) More than synaptic plasticity: role of nonsynaptic plasticity in learning and memory. Trends Neurosci 33:17-26. CrossRef Medline

Pirger Z, Crossley M, László Z, Naskar S, Kemenes G, O’Shea M, Benjamin PR, Kemenes I (2014) Interneuronal mechanism for Tinbergen's hierarchical model of behavioral choice. Curr Biol 24:2215. CrossRef Medline

Proekt A, Brezina V, Weiss KR (2004) Dynamical basis of intentions and expectations in a simple neuronal network. Proc Natl Acad Sci U S A 101:9447-9452. CrossRef Medline

Proekt A, Vilim FS, Alexeeva V, Brezina V, Friedman A, Jing J, Li L, Zhurov Y, Sweedler JV, Weiss KR (2005) Identification of a new neuropeptide precursor reveals a novel source of extrinsic modulation in the feeding system of Aplysia. J Neurosci 25:9637-9648. CrossRef Medline

Proekt A, Jing J, Weiss KR (2007) Multiple contributions of an inputrepresenting neuron to the dynamics of the Aplysia feeding network. J Neurophysiol 97:3046-3056. CrossRef Medline

Proekt A, Wong J, Zhurov Y, Kozlova N, Weiss KR, Brezina V (2008) Predicting adaptive behavior in the environment from central nervous system dynamics. PLoS One 3:e3678. CrossRef Medline

Rosen SC, Teyke T, Miller MW, Weiss KR, Kupfermann I (1991) Identification and characterization of cerebral-to-buccal interneurons implicated in the control of motor programs associated with feeding in Aplysia. J Neurosci 11:3630-3655. CrossRef Medline

Sánchez JA, Kirk MD (2001) Cerebral-buccal pathways in Aplysia californica: synaptic connections, cooperative interneuronal effects and feedback during buccal motor programs. J Comp Physiol A 187:801-815. CrossRef Medline

Santini E, Porter JT (2010) M-type potassium channels modulate the intrinsic excitability of infralimbic neurons and regulate fear expression and extinction. J Neurosci 30:12379-12386. CrossRef Medline

Santini E, Quirk GJ, Porter JT (2008) Fear conditioning and extinction differentially modify the intrinsic excitability of infralimbic neurons. J Neurosci 28:4028-4036. CrossRef Medline

Shuster MJ, Camardo JS, Siegelbaum SA, Kandel ER (1985) Cyclic AMPdependent protein kinase closes the serotonin-sensitive $\mathrm{K}^{+}$channels of 
Aplysia sensory neurones in cell-free membrane patches. Nature 313:392395. CrossRef Medline

Siniscalchi MJ, Cropper EC, Jing J, Weiss KR (2016) Repetition priming of motor activity mediated by a central pattern generator: the importance of extrinsic vs. intrinsic program initiators. J Neurophysiol 116:1821-1830. CrossRef Medline

Song J, Ampatzis K, Ausborn J, El Manira A (2015) A hardwired circuit supplemented with endocannabinoids encodes behavioral choice in zebrafish. Curr Biol 25:2610-2620. CrossRef Medline

Vilim FS, Sasaki K, Rybak J, Alexeeva V, Cropper EC, Jing J, Orekhova IV, Brezina V, Price D, Romanova EV, Rubakhin SS, Hatcher N, Sweedler JV, Weiss KR (2010) Distinct mechanisms produce functionally complementary actions of neuropeptides that are structurally related but derived from different precursors. J Neurosci 30:131-147. CrossRef Medline

Willoughby D, Cooper DM (2006) $\mathrm{Ca}^{2+}$ stimulation of adenylyl cyclase generates dynamic oscillations in cyclic AMP. J Cell Sci 119:828-836. CrossRef Medline

Wu JS, Vilim FS, Hatcher NG, Due MR, Sweedler JV, Weiss KR, Jing J (2010) Composite modulatory feedforward loop contributes to the establishment of a network state. J Neurophysiol 103:2174-2184. CrossRef Medline

Zhang Y, Liu RY, Heberton GA, Smolen P, Baxter DA, Cleary LJ, Byrne JH (2011) Computational design of enhanced learning protocols. Nat Neurosci 15:294-297. CrossRef Medline

Zhao S, Golowasch J, Nadim F (2010) Pacemaker neuron and network oscillations depend on a neuromodulator-regulated linear current. Front Behav Neurosci 4:21. CrossRef Medline

Zhurov Y, Proekt A, Weiss KR, Brezina V (2005) Changes of internal state are expressed in coherent shifts of neuromuscular activity in Aplysia feeding behavior. J Neurosci 25:1268-1280. CrossRef Medline 